DOI: 10.1515/ausfm-2015-0015

\title{
Between Absorption, Abstraction and Exhibition: Inflections of the Cinematic Tableau in the Films of Corneliu Porumboiu, Roy Andersson and Joanna Hogg
}

\author{
Ágnes Pethő \\ Sapientia Hungarian University of Transylvania (Cluj-Napoca) \\ E-mail: petho.agnes@gmail.com
}

\begin{abstract}
The paper proposes to focus on the multiple affordances and intermedial aesthetic of the cinematic tableau seen as a performative space resulting in the impression of watching a painting, a theatre stage, a shop window, a diorama, or a photo-filmic installation in which the play between stillness and motion is accompanied by a reflexive emphasis on media and the senses. Such images, described extensively by David Bordwell in his writings on the evolution of film style, are being re-evaluated through debates on the "tableau form," "absorption and theatricality" in modern art and photography (e.g. Jean-François Chevrier, Michael Fried). In particular, the aim of this paper is to examine inflections of the cinematic tableau in the films of three contemporary European authors, Corneliu Porumboiu (Romania), Roy Andersson (Sweden) and Joanna Hogg (UK), and relate them to the paradigm of the Dutch interior established in seventeenth-century painting. ${ }^{1}$
\end{abstract}

Keywords: intermedial aesthetic of the tableau shot, Dutch interior in cinema, Corneliu Porumboiu, Roy Andersson, Joanna Hogg.

\section{The Tableau Shot as a Space of In-Betweenness}

Harking back to the theatrical tableaux of early cinema and modernist practices of pictorial abstraction, the so called tableau $\operatorname{shot}^{2}$ has developed into a surprisingly versatile figure in contemporary cinema. It appears indispensable in mainstream bio-pics and heritage films where shots composed as paintings have

1 This work was supported by a grant of the Romanian Ministry of National Education, CNCS UEFISCDI, project number PN-II-ID-PCE-2012-4-0573.

2 Ben Brewster and Lea Jacobs define the tableau as: "a characteristic type of shot in early films, and a type of constructions which relies on that type of shot. This is the centred axial long shot, 
become key figures of a mannerist aesthetic and a kind of shorthand to connect the narrative to a certain period in history (see Vidal 2012). It is however, in the category of arthouse films where we see a puzzling complexity in the use of the tableau. It can be seen as a recurring device of contemplative "slow movies" that have etched out their own niche on the international film festival circuit in the last decades, lyrical documentaries, and experimental works bordering on installation art. We may recall in this respect the almost still tableaux of Pedro Costa or Béla Tarr; ${ }^{3}$ Alexander Sokurov's Spiritual Voices (Dukhovnye golosa, 1995) documenting the life of soldiers in a permanent state of war on the border between Tadjikistan and Afghanistan, which features in its first part a sublime (more than 30 minutes long) scene of a winter landscape, filmed with fixed camera, slowly changing in time; Jean-Claude Rousseau's documentary essay, The Enclosed Valley (La vallée close, 1995) with its images composed as Romantic landscape paintings; the series of tableaux depicting rural life in Michelangelo Frammartino's Le Quattro Volte (2010); or John Akomfrah's The Nine Muses (2010) alternating found footage with painterly compositions of majestic stillness. In the category of films conceived like installation pieces, the examples may include: Lav Diaz's beautiful From What is Before (Mula sa Kung Ano ang Noon, 2014), a more than five and a half hours long motion picture experience unfolding in lengthy tableau shots; Tsai Ming-Liang's Walker-series contrasting in long takes the hustle and bustle of contemporary urban landscapes (Hong Kong, Marseille, Tokyo) with the extreme slow walk of a Buddhist monk (e.g. the short films: Walker, 2012; Journey to the West, 2014; No, no Sleep, 2015), or his feature film consisting of loosely connected, single shot sequences, Stray Dogs (2013), etc. These examples, pinpointing some of my latest revelations in the field, are, however, only meant to tentatively ripple the surface of a vast area where discussions about the cinematic tableau may be relevant today. The scope of this article is in fact much narrower. Instead of an inventory of this stylistic device in different areas of world cinema, I merely propose to unravel certain paradigmatic features of the renewed aesthetic of the tableau, hoping in the process to contribute to a more refined understanding of the poetic "mechanism" of this figure. I will do this through an analysis of a more delimited corpus of films, the recent works of three European authors (the Romanian Corneliu Porumboiu, the Swedish Roy Andersson and the British Joanna Hogg). All of

looking at an interior as if at a box set on stage from the centre of the theatre stalls. Many early films consist largely of such shots, linked by intertitles; they lack scene dissection, or even alternation between simultaneous scenes. This has come to be called 'tableau construction"” $(1998,38)$.

See a theoretical discussion of the photo-filmic qualities of these in Pethő (2015). 
these authors seem to have designated the tableau as a defining element of their style, resulting in works that are very different, but that somehow still share a set of key features. A comparative analysis of their films may identify and map some of the most important inflections of the tableau form in contemporary film art.

In the broadest sense the premise of my investigation is twofold. On the one hand I situate the tableau within the interpretive framework of intermediality, viewing it in terms of overlapping forms of art and culture, with elements derived from painting, theatre, photography, performance, and new media. On the other hand, closely connected to this, and acknowledging the permutational quality of the tableau (i.e. its possibilities for variation), which has been extensively treated in the writings of Noël Burch (1979) and David Bordwell $(1981,1988),{ }^{4}$ I regard the cinematic tableau not only as a unit defined by certain fixed and flexible parameters, as a set of stylistic markers, but as a highly transgressive and performative structure. ${ }^{5}$ The tableau is always able to bring forth the intermediality of cinema as a productive in-betwenness, ${ }^{6}$ assigning the form of one medium (e.g. painting, photography, theatrical mise-en-scène) to act as a medium for a specific figure (the tableau shot) in the other medium (cinema). ${ }^{7}$ Consequently, we should try to understand the variations of the tableau shot also by mapping out the network of media connections and the dynamics of in-betweenness that they enable. The cinematic image may open up towards painterly vedutas, domestic genre scenes, theatrical arrangements or operatic tableaux performances, in other cases we have a more stylized picture, an ornamental composition, or a minimalistic play upon stillness and motion, rhythm and stasis, depth and surface, or we may behold

4 See also several entries on Bordwell's website: http://www.davidbordwell.net/blog/category/ tableau-staging/. Last accessed 05. 07. 2015.

5 The notion of performativity in this case is used more closely to its use in linguistics (as it appears in the writings of John L. Austin and John Searle on "speech-acts"), where it refers to the capacity of speech not simply to convey meaning but to carry out and action, and is not employed in its wider sense appropriated by the so called "performance theory" or "performance studies," in which it has become "an adjective that can be applied to the dramatic or theatrical aspects of a situation or object of study" (Loxley 2007, 169).

6 See more about the performativity of intermediality in Pethő (2011, 37-48). In addition I have argued elsewhere that intermediality can also be conceived as a process of "becoming" in a Deleuzian sense, something that "always 'folds' from within, emerging from the immanence of cinema's multimedial texture. As the form of one medium resurfaces within another, it always brings to the foreground a heightened sensation of imminent transgression (...) 'as if' one medium had been brought to the verge of collapsing or imploding into another without such a collapse ever taking place" (Pethő 2014, 475).

7 See in this respect the idea of Joachim Paech that "the medium formulates and the form figurates" (i.e. the medium becomes observable as form, and the form serves as a medium for the figure). According to him, intermediality can be described in this way as the process of the re-inscription of a medium as a form in the form of another medium (quoted in Pethő 2011, 40). 
images conceived in the manner of pictorial photographs, of single channel video installations, and so on.

In all these manifestations, the cinematic tableau shot draws primarily on the framed, self-contained "picture" (tableau) form in media history, on an inter- and transmedial, often self-reflexive structure (see Chevrier 2003, 2006), which has had a long, "adventurous" journey in-between media, being "dislocated" from painting (where it had its own evolution culminating in modern art displayed in gallery spaces), and adopted as a format in photography, film and installation art. As the tableau form emerges in cinema, it also brings with itself a series of general attributes inherited from painting and shared with photography and new media. The tableau shot does not merely establish or "describe" a setting, or contain a particular choreography of the characters on the screen, it is usually constructed as a standalone image, which confronts the viewer without being fragmented by intra-sequence cuts. Accordingly, it can also be described with the much debated notions of "absorption" and "theatricality" introduced by the art historian Michael Fried, who used them to define the transition from the immersive world of realist painting to modern art, minimalism and the exhibition of mere "objecthood" (see Fried 1988, 1992, 1998a, 1998b.) Although originally they were employed as conflicting terms, with the rise of large-scale photographs and video installations their antagonism was effectively called into question. ${ }^{8}$ I suggest that (especially in some of the works of the slow film canon) the recent revival of the tableau form in cinema has produced further challenges to these concepts through foregrounding the inherent duality of theatricality and absorption underlying the tableau aesthetic.

As a frontal long take, filmed with a more or less static camera, the tableau offers the impression of viewing a painting, a photograph in motion, or gives the viewer access to what seems like the interior of a box. What is common in the different manifestations of the tableau is that it sustains both a particular type of spectatorship (based on the distance maintained between the viewer and the screen), and a particular relationship between the characters, objects and the natural or architectural space visible on the screen, which all appear to be sealed off and closely interconnected within the frame of the picture. In comparison, we may remember how in classical narrative films the spectator is continually drawn into the illusory world of the screen. The mobile camera eliminates our position

8 See Fried's analysis of Jeff Wall's photo-exhibits, meticulously staging scenes of everyday life (Fried 2008), or his discussion of the anti-theatricality of Douglas Gordon's video installations (Fried 2011, 2015). 
of fixed distance, and, in the words of Béla Balázs, it puts us, spectators "in the very heart of the image." He writes: "The camera takes my eye along with it. [...] I have no standpoint of my own. I travel with the crowd, I fly up, I dive down, I join in the ride" $(2010,99)$. This identification with the camera together with the seamless editing enables a fluid orientation in space, where the spectator sees the cinematic world oblivious of its frame.

The specificity of the tableau, in the most general sense, is that it appears (in the words of Balázs 2010, 99) as an "insulated space, manifesting itself as a microcosm," to which there is no such fluid access as a mobile camera would allow, instead it is something we are not in the middle of, but something we always watch from the outside. So while such a shot preserves the voyeuristic distance of spectator and screen, inasmuch as we view the scene from the same fixed position for a considerable length of time, this is a construction in which we are more in the position of the "pensive spectator" described by Raymond Bellour (2007) and Laura Mulvey (2006). In Bellour's words, the relative stillness of the images 'tempers the 'hysteria' of the film [...]. Though drawn more deeply into the flow of the film, the spectator is simultaneously able to reflect on it with a maximum of intensity" $(2007,122)$. At the same time, observing characters absorbed in their action and interacting with each other in a static shot, as if arranged on a canvas, a stage, or in a photographic light box, may paradoxically heighten both the sensation of reality and artificiality, producing the effect of an artification or exhibition of an everyday experience. In this way, the more "vernacular" tableau shot appears to take shape according to a similar, yet somewhat reverse principle as the tableau vivant proper (i.e. the explicit reproduction of a painting), in which, according to Brigitte Peucker (2007, 31), the flesh of human presence introduces the "real" into "the image," merging reality with representation. Whereas the tableau vivant proper creates the illusion of pictures coming alive, the tableau shot reframes a "slice of life" within the aesthetic constructedness of a picture. Accordingly, both the tableau vivant and the tableau shot build on tensions ensuing from the duality of the illusion of the immediate access to the real and the perceivable mediation of the "image." The tableau as a flexible template in film modulating in-between life and art is able to paradoxically reconcile immersion with abstraction, even a minimalist reduction (and parametric variation) of formal elements with multisensory aestheticism.

In what follows, I will discuss three types of inflections of the tableau based on the works of Corneliu Porumboiu (a prominent representative of the so called Romanian New Wave, whose films combine austere minimalist tableaux with 
explicit media reflexivity), Roy Andersson (known for his films compiled of grotesque, surrealist vignettes mixing elements of painting, theatre and opera), and Joanna Hogg (experimenting with low-key realism combined with a high degree of stylization in the image, revitalizing the role of architecture in the intermedial texture of cinema). Although concerned with diverse topics, these three authors are all remarkable for the way in which they excavate the affordances of the tableau's intermedial and performative space, relying on the combination between realism and artificiality, and forging not only highly original cinematic styles based on the rigorous aesthetic of the tableau shot, but also conceptualizing the figure of the tableau.

\section{The (Transmedial) Paradigm of the Dutch Interior}

Analysing Carl Theodor Dreyer's early films, David Bordwell explains that "as image and structural principle the tableau is firmly tied to a tradition of what we might call chamber art. Historically, the stylistic premises of this tradition are the perspective discoveries of quattrocento panting and theatre, whereby space is conceived as a cube to be filled by human figures. With the increasing secularization of subject matter, in northern baroque painting, chambers housing the Virgin or various saints were replaced by everyday interiors, the bedrooms, parlors, and kitchens of bourgeois homes" in which we see people engaged in everyday activities $(1981,41-42){ }^{9}$

In fact, Dutch painting of the Golden Age can be seen as a key influence moulding not the tableau shot in general, which can be much more diverse as already suggested, but one of its fundamental types, the box-like, architectural tableau of domestic interiors. This intersection of the tableau shot with the visual paradigm established by the Dutch masters produces a highly performative configuration due to the fact that the Dutch interior is an especially complex model in painting. It does not only consist in a certain geometric organization of space, and is not only relevant from the perspective of a cultural anthropology of space, it also appears as a sophisticated, reflexive structure of in-betwenness which defines its aesthetics. With their recurring motifs of doors and windows, leading the viewer's gaze through a series of thresholds, and staging the scene in depth, these paintings give prominence to architecture (featuring dwellings and churches as their main topic), and to an architectural division of space,

9 We can compare in this respect the paintings of Antonello da Messina: St. Jerome in his Study (1460-1475) and those of Pieter de Hooch or Samuel van Hoogstraten in Figs. 1-4. 
as well as the idea of liminality in an unprecedented way. Besides reflecting a way of life, a social and gendered stratification of a world of everydayness and domesticity ${ }^{10}$ by giving access to the anatomy of the Dutch household with the depiction of kitchens, pantries, living rooms, studios, these paintings introduce a play between the foreground and the background, interior and exterior. They stage a "plunge through," as suggested by the literal meaning of the Dutch word, doorsien, applied to this technique: an entrance for the eyes to a deep interior, often with a tiny back room, or an access to a courtyard, a window to the outside, where the scene assimilates the street and the city beyond (Hollander 2002, $5-8$ ), and where the space of the tableau is conceived in-between enclosure and openness, reaching beyond the demarcation of a private and public world. The human figure appears in these paintings caught in theatrical ${ }^{11}$ poses "wavering between two worlds," like the "doorway-bound" eavesdropper that we see in the famous series by Nicolaes Maes who is always "equally protagonist and beholder, spectacle and spectator, both within and without the pictorial narrative" (Cole 2006, 20). Maes's Eavesdroppers thematize the latent tension between secrecy and disclosure, between the enclosure of a private world within the cluster of rooms and the gaze that repeatedly penetrates it through the apertures in Dutch "chamber art." [Figs. 7-8.] The division of the inner space also enables an intense play upon framing and de-framing, upon the visible and the invisible, as we are allowed to peep through doors and windows, ${ }^{12}$ yet the rooms are all fragmented, there are inner walls between doors and windows impenetrable to the gaze, and we also have all kinds of objects occluding the view. ${ }^{13}$ Through the opening of doors and windows, what is outside (the "real world" beyond the canvas) becomes an image for the inside, thus the viewer is simultaneously inside and outside the painting (cf. Hammer-Tugendhat 2015, 292). Therefore the art historian Victor I. Stoichita described these as "self-aware images," explaining how, in effect, "the view through the doorway became the metaphor of painting" $(1998,54)$. Dutch

10 As Charles Rice's book summarizes, these were notions which enhanced the popularity of these paintings two centuries later, in the nineteenth-century, when "concepts such as privacy, intimacy, comfort and home" became relevant in the context of the emerging importance of bourgeois family life as the nucleus for the idea of the Dutch nation (cf. Rice 2007, 22).

11 Both Westermann (1996) and Hollander (2002) emphasize the theatricality of Dutch genre painting, with characters also "exchanging" looks with the viewer, comparable to asides on the stage.

12 Samuel van Hoogstraten's famous Peepshow with Views of the Interior of a Dutch House (16551660), exhibited in the National Gallery in London, with its actual peep-hole embodies this structure, combining an enclosed box hiding a view that is magically opened up through the aperture inviting the viewer's gaze deeper and deeper inside. [Fig. 5.]

13 See more about the play upon the visible and invisible in seventeenth-century Dutch painting in Hammer-Tugendhat (2015). 
interior painting appears in this way also as a secular investigation into the nature of images after the age of iconoclasm, framing a fragment of "life" alongside a subtle staging of "imageness" itself (i.e. the perception of the world as an image, where the doors/windows to the outside are also doors to the "inside:" means for a self-reflexive examination of the art of painting, reinforced also, alongside the multiplication of inner frames, by the presence of pictures hanging on the walls).

In her seminal work on Dutch art, Svetlana Alpers emphasized that "the Dutch present their pictures as describing the world seen rather than as imitations of significant human actions," allegories or narratives (1983, xxvi), and considered that this meticulous "art of description" reflected a way of thinking determined by contemporary scientific approaches like optics or mapmaking (attested by the maps, globes, and telescopes appearing in these depicted homes).

On the other hand, the tight assemblage of elements of these domestic interiors and niche pictures have also been associated with the structure of emblems (cf. Hollander 2002, 77-79). And just like the emblem books, these dense painterly "descriptions," often convey a covert moralizing intent (e.g. Hammer-Tugendhat 2015). ${ }^{14}$ Last but not least, as Hollander states, "the use and reuse of particular formal conventions reflects the formulaic, repetitive nature of Dutch art" $(2002,6)$ which institutes the Dutch interior compositions as one of the most recognizable "parametric scheme" in painting, easily imitated or remodelled in later art, and (trans-medially) adopted by the tableau mode in cinema. ${ }^{15}$

The specific permutations of the tableau that we see in the films of the three authors selected for analysis can all be interpreted starting from the paradigm of Northern baroque painting summarized here. In all of them we find that the tableau form is closely connected to architectural space opening up through inner frames, with protagonists inhabiting these spaces who are portrayed in liminal situations. But instead of any dramatic action they are all caught in mostly static, painterly poses, with dialogues delivered in single takes as if being on a stage. Although there is no clearly moralizing intention, the tableau form does carry an implicit social-philosophical commentary in each case, reflecting on the social stratification and isolation of individuals, or on different ways of life encapsulated in this visual construction. In the vignettes of Roy Andersson's "trilogy of human condition," Songs from the Second Floor (Sånger från andra våningen, 2000), You, the Living (Du levande, 2007), A Pigeon Sat on a Branch

14 The moralizing purpose is sometimes accomplished through the condensed meanings of proverbs reflected in the satirical genre paintings.

15 For an excellent analysis of the adaptation of some of these parametric elements, i.e. the use of doors, windows in cinema (in the films of Luchino Visconti), see Blom (2010). 
Reflecting on Existence (En duva satt på en gren och funderade på tillvaron, 2014) we enter a series of grotesque dollhouse structures with an unsettling merger of the notions of public and domestic: public spaces (hospital rooms, corridors, funeral parlours, etc.) are composed as Dutch interiors, domestic settings blend in with impersonal locations (pubs, restaurants, train compartments filmed as if they were people's homes), and homes appear bleak as offices. In Andersson's grotesque vision we can never be sure whether to understand this as the extension of the "format" of domesticity in a highly atomized and compartmentalized life of a welfare society, or as the complete erasure of it. We invariably see the life of his characters contained within cubic spaces, with scenes composed in a complex staging in depth ${ }^{16}$ (often achieved with showing the box-like space not frontally but from an angle, see Figs. 9-12). In one particular scene of A Pigeon Sat on a Branch Reflecting on Existence, there is even a minimalist visual pun about conceiving a tableau scene as a box to be filled with human figures as we see a cubicle and people popping up in front of it to wait in another box-like space. The pun has its match in another scene, in which we see with a flamboyant anachronism the eighteenth-century Swedish King Charles XII and an army of mounted horsemen slowly marching into a present-day bar. Realism blends in this way with the surreal and the absurd.

In Joanna Hogg's films people inhabit a series of "borrowed" or transitory spaces filmed as a cluster of rooms opening towards other rooms. Her well-to-do, upper-middle class heroes are on holiday in Unrelated (2007), and in Archipelago (2010), on the verge of important decisions concerning their lives (in each case we see family groups who are not at home, merely occupying rooms), in Exhibition (2013), the married couple is just about to move on and sell their house they live in. All three of Joanna Hogg's films give prominence to the structured interiors of houses with dynamics of family and social relations reflected in architectural spaces. [Figs. 13-20.] In Archipelago, the tiny attic room with slanted walls assigned to the son mirrors his subdued position in the family and is in grotesque contrast with his tall stature. (Meanwhile the assertive sister takes possession of the largest room with a king size bed. See Figs. 17-18.) In the same film, the young woman hired to cook for the family is shown in conversation with the hunter who brings the game to the house [Fig. 20] in a composition that is familiar from the courtyard scenes in Peter de Hooch's canvases [e.g. Fig. 6], or the liminal situations of Dutch paintings displaying trades with travelling salesmen coming

16 See a detailed examination of Andersson's parametric technique of staging in depth in Hanich (2014). 
to the kitchen doors. The tableau form contributes to a revision of the aesthetic of realism in Hogg's films, in which the traditional emphasis on (working) class issues that defined earlier trends of realism in British cinema gives way to capturing everyday moments of private lives and a feeling of bourgeois ennui. ${ }^{17}$

In Porumboiu's films, again, the demarcation between public and domestic is continually blurred. In 12.08. East of Bucharest ( $A$ fost sau n-a fost, 2006) and in Police, Adjective (Politist, adjectiv, 2009) the makeshift TV studio, the police station and the apartments where the protagonists live look not only similar, they are in fact the same specimens of rooms in typical East European blocks of flats built during the time of communism. In When Evening Falls on Bucharest, or Metabolism (Când se lasă seara peste Bucureşti, 2013) the film director protagonist discusses his film project in his own apartment presented in the same way as Dutch interiors. He also makes love to the leading actress here, but the empty walls and basic furniture make it look more like a film stage waiting to be properly furnished, than a home. Equipped with a brand new Apple computer the apartment speaks of a new way of life mimicking Western models, and appears as a clinical and impersonal "any space whatever" in the middle of the nation's capital. In this way, the tableau becomes in Porumboiu's films a vehicle for an ironic depiction of the post-socialist spaces of life, where the miserable uniformity of communist architecture slowly gives way to the chaotic entanglements of offices and homes brought about by the new petty entrepreneurs who set up their businesses in the old housing projects by repurposing private apartments, or to the dull emptiness of new domiciles, symptomatic of a desperate effort to sever all palpable ties to a specific cultural past.

\section{From "Chamber Art" to Diorama, and the "Sadistic Irony" of De-Framing}

Porumboiu's 12.08. East of Bucharest, a deadpan satire of post-communist Romania, is a film that is built entirely on re-framing and de-framing, both visually and conceptually, this traditional tableau construction originating in the Dutch interior. The story of the film is simple: sixteen years after the revolution, in a small town East of Bucharest, on the anniversary of Ceauşescu's infamous last speech just before he was ousted, the owner and talk show host of a shabby local TV studio, for lack of better eye witnesses, invites a cranky old pensioner

17 David Forrest describes this type of realism in Hogg's films as the "shift from the public to the personal" $(2014,68)$, but does not mention the aesthetic of the tableau prominent in her films. 
and an alcoholic schoolteacher to discuss whether there was a revolution in the town or not. The crucial questions to be answered are the following: did people come out to protest against Ceauşescu's regime before the dictator fled in his helicopter at exactly 12.08 on 22 December 1989, or did they react only to the news of the events in the capital city? So was there or wasn't there a revolution on a local scale in this provincial town?

The film begins with the introduction of the main characters and reaches its climax with the talk show itself, with a last scene at the TV studio. In the first part we see a series of tableaux depicting domestic interiors presenting each of the talk show participants in their natural "habitat" in the manner close to what Bordwell described as "chamber art." As we pass from one drab interior to another, the poorly lit spaces stuffed with heavy furniture are further narrowed down by massive doorways acting as interior frames, which, in contrast to Dutch paintings, do not appear as means to extend the space, but to partially block our field of vision. In such shots, as the camera does not move closer to the human figures or follow them around, people become just as important as the objects filling up the space. Bordwell's remarks on Dreyer's technique are valid in this case as well: "our attention swerves to objects and furnishings; details of these chambers become as clearly articulated as figures" $(1981,48)$. Paradoxically, such compositions constructed around the characters thus manage to de-centre their subjects even though they are physically placed in the centre by pushing them into the background, and by diverting our attention towards other items in the rooms, pictures on the wall or TV sets turned on. [Figs. 21-24.] Porumboiu generates in this way not only a low-key cinematic parody of the tableau mode originating in genre painting but also an implicit ironic social commentary.

In Roy Andersson's films there are also several scenes which use the affordances of the "chamber art" structure for explicit satirical purposes, to emphasize the absurdities of domestic alienation (e.g. in A Pigeon Sat on a Branch Reflecting on Existence, the housewife preparing dinner in the kitchen and not noticing the death throes of her husband, who is having a heart attack in the other room, Figs. 25-26), or to create twisted visions of domestic bliss (in You, the Living, there is a young girl fantasizing about being the bride of a rock star, and we see people staring at them through the windows of a house departing with the newlyweds like a train with the crowd standing on the platform). [Figs. 27-28.]

Due to the frontality of the shots, the tableau offers a vantage point from where the spectator's gaze may behold the image as a container, and from where onscreen space becomes not merely staged in a theatrical mise-en-scène, but can be 
conceived as a display, an "exhibited" space. In some of Joanna Hogg's shots, the low camera angle also contributes to the feeling of seeing characters as if moving on a stage even when they are outdoors [Figs. 29-30]. ${ }^{18}$ Moreover, characters in these films often appear to be boxed in a glass case, giving the impression of watching an arrangement in a shop window, making the passage in the films from "domestic chamber" to a kind of public diorama [Figs. 31-32]. ${ }^{19}$ Porumboiu's 12:08. East of Bucharest makes the most of this with a simple technique in its long scene transporting the talk show participants from their home to the venue of the TV broadcast in which the two men are shown through the windshield, and with the small TV studio filmed like an aquarium [Figs. 33-34]. Here, the disembodied voices of the people who phone in during the live broadcast even indicate the external vantage point of the spectators' gaze. Glass boxes (large windows, glass storefronts) framing the characters are perhaps most frequently used by Andersson in scenes ranging from comical to the morbid [Figs. 35-38] culminating in the absurd conceptualization of the outside perspective of the viewer in his Pigeon. Inspired by Pieter Bruegel the Elder's painting (Hunters in the Snow, 1565) where birds look down on humans, Andersson shows a taxidermied pigeon in a museum both as observer and observed, suggesting a reversibility of roles (within this doubly folded diorama), with the humans lingering in the exhibition space pale as waxwork figures to be contemplated by the stuffed animals in the glass cases [Figs. 39-40].

In the end of Porumboiu's film, when the panellists take their place in front of the camera, a young cameraman begins to film them in a shaky, amateur video style. The scene can be interpreted also as an ironic, self-reflexive reference to this being the new, fashionable way to do video recordings, and, as such, being in contrast with the "old," static cinematography made with cameras on tripods, implicitly with the tableau aesthetic employed throughout the film. Here, through this clumsy camera work we witness a hilarious disintegration of the tableau (and of the neat arrangement of the three figures, the white haired pensioner and the morose, alcoholic teacher sitting on each side of the pompous talk show host, as an ironic holy trinity). [Figs. 41-44.] The images become de-framed and askew, the panellists move around and fidget uncontrollably while the telephone interventions of the viewers make the scene more and more cringe-worthy. In

18 The same sensation of exhibitedness is achieved in both Unrelated and Archipelago, for example, through presenting the characters seated in closed group compositions outdoors, surrounded by the picturesque landscape, as if they were posing for a painting.

19 Similarly, in Hogg's Exhibition we are even allowed to watch people in a scene from above through a glass window, as if looking down at an exhibition case [Fig. 32]. 
his seminal article on "décadrage," Bonitzer speaks about "the sadistic irony of off-centre framing” (2000, 201), and Porumboiu uses the visual gag of characters trying to stay in the frame or being pushed out of frame in a sophisticated interplay between framing and de-framing, between the still photograph of the town hall in the background and the chaotic movement in front of it, which ultimately calls attention to the principle of decentredness, of being off-centre, out-of-frame as the main metaphor for the whole film, which presents the failed attempt to re-frame "the everyday" in a provincial town, far from the centre of action in Bucharest, as "revolution."

A similar direction of inflecting the tableau towards ironic de-composition, fragmentation is perceivable in Hogg's films, where we also have a strong conceptualization of the characters' decentredness supported by a rich signification of inventive de-framings ranging from melancholy, isolation, insensitivity to pure visual abstraction [Figs. 45-48]. We observe, for example, Anna, the heroine of Unrelated (played by Kathryn Worth) in a series of anxious attempts both literally and symbolically to stay "in the frame," to maintain her social and emotional relations (to her partner, who did not join her on this holiday, to her friends, who most likely invited her out of pity and consider her an odd fit in their circles), pathetic in her efforts to be both part of the "olds" (as the teenagers call their parents), and join the group of youngsters. We see the mother in Archipelago talking on the phone in classic niche painting compositions as she repeatedly struggles to bring the absent father "into the picture." [Figs. 49-50.]

\section{In and out of the Box: the Theatricalization of the Tableau and Joanna Hogg's "Liquid Intelligence"}

As we can see, the tableau shot is usually remarkable not only for what it boxes in but also for what it boxes out. As opposed to the notion of "off-screen," which denotes according to Pascal Bonitzer (2000) an imaginary/fictional dimension, "off-frame" can be conceived as an actual, material space, outside the cutting edge of the frame encompassing both the extension of the diegetic world and the space of the spectator facing the screen. Bonitzer also remarks that the "'out-offrame' multiplies the power of the representation" $(2000,198)$, and these films corroborate this assertion by enhancing the play between what is in and out of the frame, between what we see and what we hear. Beside the allusion of the doorways, the duality of off-screen and off-frame is also continually present in these films through the repeated action of characters speaking on the phone, 
or communicating with someone beyond the visible space, but stuck in the cinematic frame. The first half of Porumboiu's 12:08. East of Bucharest presents the protagonists in domestic tableau scenes while all of them have lengthy conversations on the phone, thus opening up each scene and interconnecting the separate "boxes" they appear in.

A recurrent motif for Joanna Hogg is to set up scenes in which emotionally charged dialogues are placed beyond our vision while other characters can unwillingly overhear them, or are actively eavesdropping. During the vacation in Italy in Unrelated there is a terrible row between father and son that we cannot see, only hear, as they are inside the house, while the camera remains with the rest of the family and friends, who are lounging outside by the pool and listening to the quarrel in a long, awkward scene. In Archipelago, Hogg seems to adapt the situation of Nicolaes Maes's Eavesdropper series, ${ }^{20}$ with the open doorway, the empty hallway, the figure of the listener standing on the threshold, only this time without the joviality of the scene and without the scenario involving sexual indiscretion. The "mediumship of the listener," as the title of David Toop's book (2010) suggests, involves here a "sinister resonance" indeed. The picture is dark, grey, as if filtered through murky water, and the figure is weighed down not only by the words he is not supposed to hear, but also by what remains out of sight (as Toop explains "the eavesdropper cannot see, only look out into the unknown future," 2010, 77). It is Edward, the irresolute young man (played by Tom Hiddleston), who does not really know what to do in life, and is spending a holiday with his mother and sister before leaving for a volunteer job in Africa. He is overhearing the sobbing and shouting, self-humiliating mother talking with her husband on the phone: a sight that he is surely not eager to behold. Although we can observe him in the middle of a complex theatrical staging, the eavesdropper's position is that of a self-erasing liminality: not only does he not see, he also draws back so as not to be seen. What used to be a depiction of the life of servants or inquisitive housewives in Dutch painting (and is actually paraphrased in some of Hogg's scenes involving the cook), becomes here a powerful portrayal of Edward's invisibility in the family. Despite being seemingly in the centre of the whole situation (it is because of him that they are supposedly there), he has very little say in matters regarding the family, even his repeated attempts to communicate with the cook remain too feeble to amount to a proper relationship. He remains a lingering, liminal figure in the shadow of an open doorway. [Figs. 51-54.]

20 The theme was so popular at the time that Maes himself painted six versions between 1655 and 1657 [e.g. Figs. 5-6]. 
Such scenes of eavesdropping make us aware of the way these spaces fold into interconnected boxes that can both reveal and conceal, draw us in as complicit witnesses and shut us out, with characters acting at the same time as go-betweens and caught in the vertigo of frames, emphasized through the recurring in-depth compositions of hallways. In Hogg's previous film, as the title of Unrelated already suggests, Anna's position within the group is not only an outsider, and she is not only single (and becoming painfully aware of being unmarried and childless), but she is trapped in her role conceived as an extension of the marginal figure of the eavesdropper, listening in at conversations most of the time, and observing how other people live their lives.

Porumboiu's Police, Adjective adopts a similar mechanism of looking and listening in at a scene (staged as a compartment of the tableau) within the framework of a narrative derived from detective films. Here, in the figure of the policeman who is surveilling three high-school students suspected of using drugs, we don't just observe the characters from a distance, but observe a character who is himself observing other characters from a distance and moving continuously on a meandering trajectory around the same typically miserable post-communist blocks of flats, garages and sports grounds, in and out of spaces presented as boxes, again in a string of tableaux. [Figs. 55-58.]

In Michael Fried's view, the realist tradition in painting presents figures that are absorbed in their daily activities and are totally "oblivious" of the viewer (resulting in a tableau that is "hermetically" sealed off from the world surrounding it). Modern art, however, relies on the presence of the viewer in front of the artwork; its constructedness is obvious and the awareness of the spectator's gaze (the quality he names, "theatricality," "to be seen-ness") is encoded within the picture. On the one hand, the alternation of the "hermetically sealed," realistic scene with its opening up through diegetic off-screen and off-frame spaces, and the introduction of characters as observers or eavesdroppers already introduces a kind of stage theatricality into these films (similarly to the semantics of Dutch interior paintings). On the other hand, the films also seem to expose the clash between the absorptive features of the scene and the awareness of the image as artificial construction through the reflexive double framings and by way of overwriting classic "transparency" in the moving image with perceivable forms of mediation, so that many scenes display the quality of imageness, a theatricality of representation as the most striking quality. Andersson's one-shot sequences convert everyday situations into highly stylized images under the influence of the painters like Hieronymus Bosch, Francisco Goya or Otto Dicks. The tableau intended as a cinematic paraphrase of Jean-François 
Millet's Noonday Rest (1866) ${ }^{21}$ is a beautiful example of this. [Figs. 59-60.] Keeping just a few gestural and chromatic elements to remind us of Millet's composition, but creating an image which is at the same time remarkable in its serenity (the intimacy of the couple, the faithful family dog, the peacefulness of the scene) and in its bleakness (with the isolation of the couple, the stretch of dusty earth at the dreary periphery of the urban landscape), the tableau is subordinated to no narrative, merely "exhibited" in a long take for us to see and contemplate as a single picture.

The interiors of Joanna Hogg's Archipelago appear in an almost monochromatic palette, recalling the pale, melancholic interiors in the paintings of Vilhelm Hammershøi, while some of the frames of Exhibition look like the paintings of David Hockney. Moreover, in Archipelago the characters themselves view the world in terms of painting as they pass the time by learning to paint and have long conversations about it with a painter, Christopher, who acts both as a friend and a tutor, maybe even standing in for the absent father (played by the real life landscape painter, Christopher W. Baker). [Figs. 61-62.] In Exhibition we have a couple of artists living in a very artistic house ${ }^{22}$ ("all verticals, reflecting windows and sliding partitions," ${ }^{23}$ Figs. 63-66) and where the female protagonist is busy transforming her own body into art: she is preoccupied with exhibiting herself as a kind of re-embodiment of Gian Lorenzo Bernini's Ecstasy of Saint Teresa (1647-1652), studying the picture on her computer and in books, trying out poses, costumes and props, putting on a private "performance" (most likely as a rehearsal of an art project to be presented later in a gallery). This, however, does not seem like some kind of identification with the saint, more like a fascination with the rapture expressed by Bernini's famous sculpture, as she herself is fixated on her own body and sexual desires. [Figs. 67-70.] Still her self-exhibitions seem to be more abstract and restrained, something that is more in line with the stark modernism of the architecture of the house and less in tune with her much more ardent sexual fantasies (that we learn of in other scenes). Like the figures appearing in Dutch interior paintings, who are always in close relationship with the architectural space, Joanna Hogg's characters have been devised to "appear as if they might almost be figures in a painting, placed within the frame provided by the house." ${ }^{24}$

21 Andersson speaks about this in the commentary available on the DVD edition of the movie.

22 Designed by James Melvin in 1969 and redesigned by Sauerbruch Hutton Architects sometime after the 1990s.

23 Exhibition, press book: http://www.kinolorber.com/data/presskit/EXHIBITION_pressbook.pdf. Last accessed 25. 08. 2015.

24 See the film's press book: http://www.kinolorber.com/data/presskit/EXHIBITION_pressbook. pdf. Last accessed 25. 08. 2015. 
If we dissect this modulation of the tableau space more closely, we will find that in fact Porumboiu and Hogg define two characteristic directions in which such a duality of absorption and theatricality can be polarized within the cinematic tableau, as the following brief subchapters will present.

\section{a) Realism vs. Abstractification}

In Porumboiu's Police, Adjective we see the young policeman, Cristi completely absorbed in his daily activities, in a naturalistic environment, deeply embedded in his world (as the series of inner frames suggest), and there is no scene in the film which would show us his subjective viewpoint, we always behold everything from the "outside," watching it all perceptibly from somewhere offframe. ${ }^{25}$ [Fig. 71.] The tableau shot appears here not as a vehicle for satire, but as a minimalistic container for reality presented as a fragment torn from a larger whole, a "found object," framed by the viewfinder of the camera. Moreover, a self-consciousness about language runs as a leitmotif in the film, people in this film don't just engage in conversations, they pedantically dissect the meaning of words, the relationship between signifier and signified (e.g. the scene between Cristi and his wife, arguing about the lyrics of a pop song). In addition to this, we see an increased emphasis on different forms of writing: ranging from the graffiti in the street to the handwritten police report and to the printed page brought into close-up. The final face-off about semantics brings all these elements together, and appears as a cynical literalization driving to the extreme the mechanisms of distanciation, abstraction (or theatricalization) already manifest in the visual construction of the film. Here the policeman, who has been reluctant to arrest a teenager for smoking a few hash cigarettes, is ordered by his commander to look up the meaning of the words "conscience," "moral," "law," and "police" in a dictionary, and in the end we see how detailed field tactics to apprehend the kid are chalked up on a blackboard. Thus, the letter of the law imposed with the authority of the police prevails over the qualms tormenting the young detective. Instead of the act of "de-framing" that emerged as the ultimate metaphor in 12.08. East of Bucharest, here we have a film which is built on the structural principle of "en-framing:" containment, entrapment, the definition of the indefinite (i.e. putting things into a box, underscored by the image of the grid, of various inner frames), and reveals a process of brutally overwriting presentation with

25 Thus, our presence as spectators is inscribed in the film's techniques devised to produce images to be seen, to be comprehended at one glace as a tableau. 
representation. [Figs. 73-76.] The scene happens to be also the most rigid and meticulously composed visual tableau, featuring once again an improvised panel of three people arranged symmetrically in a room. The decorative bowl of fruit brought in and placed in the middle of the table even brings back a touch of the deadpan humour based on incongruities that dominated Porumboiu's previous film, not only because it is out of place in a police station, but also because it reminds us of the conventional symbolism of the holy trinity in Orthodox icons (as we see it, for example, in Andrei Rublev's Troitsa from 1425-142726). [Figs. 77-78.] This last scene stages a kind of "theatre of the absurd" conceived as a "theatre of the abstract" by playing off the objectification of written language against the "absorptive" realism of the images. Police becomes thus the attribute of the procedure in which subjective conscience is stifled by bureaucracy, and the complexity of reality is traded in for entries in a dictionary.

\section{b) Liquidity vs. Dry Structure}

There is a wonderful short essay written by Jeff Wall which defines photography as the co-presence of "the 'liquid intelligence' of nature with the glassed-in and relatively 'dry' character of the institution of photography" (Wall 2007, 109). Defining this "liquidity" as the "natural form, with its unpredictable contours," "an expression of infinitesimal metamorphoses of quality," Wall speaks of Tarkovsky's Solaris (1972) in which scientists study an intelligent ocean that is studying them in turn, and concludes with the sentence "in photography, the liquids study us, even from a great distance" $(2007,110)$. If we consider everything that is optical, geometrical, technical, architectural in the way the cinematic tableau is assembled as a means for each frame being "glassed-in," then we may find that Hogg's films inflect the dichotomy of immersiveness and artificiality in the tableau into a similar opposition between "dry" structure and sensual "liquidity." This is achieved in the first place by alternating clusters of architectural spaces, cubic rooms with picturesque and sensuous outdoor scenes. One of the first images of Archipelago shows Edward, who has just landed on the small island of Tresco, perched inside a small van with its back open, being transported to their holiday villa, smiling at his sister and mother who follow on a bicycle. As we see him boxed in, the rectangular form of the van contrasts with the branches and leaves flying around with smudged contours on each side of the van speeding to its destination [Fig. 79]. This juxtaposition of the "liquidity" of nature and of

26 The correspondence was suggested by Pop $(2014,145)$. 
the rigid, mechanical frame around the character condenses like an emblem the antithesis manifest in each of Hogg's films. Interiors composed in accordance with the paradigm established by Dutch paintings are counterpointed with long sequences in which the theatrical or architectural gives way to the pictorial (that Christopher, the painter defines in Archipelago as "chaos," something "not solid or anchored"). We have airy shots featuring all the elements of nature (earth, water, vegetation in exotic shapes, rocks, sand, wind, etc., see Figs. 79-82) to convey a sensuous context for the modest ambitions of hedonism of these characters, who take walks, immerse themselves into pools of mud, eat exquisite food prepared for them by a private cook, or make art. In these shots the cinematic tableau taps into the implicit sensuality of the scenes in genre painting, as Hogg's films seem to celebrate in their own, understated way the full sensorium. ${ }^{27}$

Liquidity, on the other hand, is also achieved by building a whole "aural landscape, ${ }^{, 28}$ a rich universe of sounds. ${ }^{29}$ Hogg uses no musical score in her films, just the subtly amplified sounds of the environment. We hear the rustle of the leaves, the wind in the trees, the clinking of the spoons in the teacups, the song of birds, or the hammering noises of the construction workers on the other side of the street. This ambience of sounds does not only announce the presence of a world outside the frame and underscore the sensory, overflowing opulence of the tableau, it also reminds the viewer of the fault line between the discursive and the non-discursive, perceptual elements of the cinematic image. In the meanwhile, the protagonists appear in abeyance, being deprived of a classical dramatic structure, they remain stuck in the rigidity of the tableau. Moreover, Hogg's "glassed-in" figures are not only repeatedly shown gazing beyond the frame, scrutinizing the unknown, caught in poses reminiscent of paintings, but as the large windows in Exhibition fold the outside world onto the inside through the multiple overlapping reflections and through the symphony of the city penetrating the walls, a unique reciprocity emerges, the "liquid intelligence"

27 Dutch paintings also manifest a visible ambition to portray the totality of the senses, together with a similar opposition between the order and control of geometric shapes and the randomness or the chaos of sheer sensuality that can disrupt the tranquility of the scene (achieved, for example, through the presence of vegetation exposed to the elements, children that can prove uncontrollable in any moment, cats and dogs walking into the frame, birds just about to burst into song).

28 Joanna Hogg speaks about this in an interview, declaring: "for me the aural landscape of the film is as important, if not more important, than the visual landscape." (See: http://www. littlewhitelies.co.uk/features/articles/joanna-hogg-2-26487.)

29 Toop has demonstrated that Dutch paintings are also remarkable for evoking a variety of sounds: "the materiality of sound also flows through these supposedly secure and enclosing interiors" $(2010,105)$. 
of photography also pours over, and (to paraphrase Wall) seems to "study" these people from a not too great distance. [Figs. 83-85.]

\section{From "Black Box" to "White Cube," and Vice Versa: the Metabolism of Contemporary Slow Cinema?}

In certain respects, Corneliu Porumboiu's When Evening Falls on Bucharest, or Metabolism (2013), Joanna Hogg's Exhibition and Roy Andersson's trilogy all seem to employ the tableau as a flexible means to make tentative moves towards the format of expanded cinema within cinema. The relative autonomy of the carefully elaborated tableaux, the repetition and permutation of a few basic visual components, the lack of classical narration are all elements which connect them with large screen gallery films. People in these films do not walk into rooms, they walk into "spatial arrangements," or enter visual environments resembling paintings, so much so that these images and spaces become main protagonists in themselves.

Porumboiu's When Evening Falls on Bucharest adds an explicit reflexivity to this particular expansion of the tableau form towards long take sequences characteristic of installation art. In the very first shot of the film we see a man and a woman, a film director and his actress, from behind, in the interior of a car, as if sitting in front of a movie screen. The dialogue is about the difference between analogue and digital film, how one cannot shoot more than 11 minutes using traditional film stock, and how digital technology enables the extension of the shot almost indefinitely. Accordingly, the film itself is constructed of a series of long takes of the two protagonists (and occasionally a third person) sitting and talking. The effect is paradoxical, while it makes visible the structural limitations of its own analogue medium, ${ }^{30}$ it actually seems to demonstrate the real time effect enabled by digital technology; as we watch, these scenes run much longer than we are used to in a conventional fiction film. And in this fragmentation into autonomous one take sequences, we have an even more pronounced emphasis on the inherent qualities of the tableau shot as each element of composition becomes magnified. We see a space fluctuating between haptical and optical (i.e. between an actual room allowing the protagonists to move around, and a mere frame with the figures appearing as in a stretch of a frieze, pushed against a background). [Figs. 85-88.] We can savour each of the audiovisual ingredients and experience it in "a slow mode," just as we would do in a video installation that runs in a loop

30 The film was shot using traditional film stock. 
(and does not have the necessity to include elements of theatrical drama). What we see are a series of permutations: the shot in the car is repeated twice (once at night, once during daytime); there are two scenes in Paul's apartment, followed by three scenes at the restaurant and the bar, concluding with two scenes in the trailer used for the purposes of the film shoot. So we may wonder: is analogue film being framed by a digital medium in these prolonged tableau shots, or vice versa? Is the nostalgia for the limitations of analogue film poured into a form tailored by digital cinema? Furthermore, does the film self-reflexively enact the passage of moving images from the traditional "black box" of the movie theatre to the "white cube" of the modern art gallery, ${ }^{31}$ or their "reflux" (the content of a gallery movie poured into a fiction film), as the "metabolism" of slow cinema?

In this inflection of the cinematic tableau, space appears something that is not lived in but consumed, discarded, rotated within the string of autonomous sequences. Roy Andersson, in particular, is famous for his elaborate way of conceiving and constructing each scene as an individual installation piece, involving artificially built sets in a studio. The scenes appear as a series of dioramas, or compartments of a revolving stage, where certain settings return, but the emphasis is on fragmentation and on the episodes that could also be watched as independent shorts. ${ }^{32}$

We also see this in the way in which the protagonists in Joanna Hogg's films use up their spaces and then leave. Both Unrelated and Archipelago are bookended by the arrival of the protagonists at a house where they spend a few days, and their departure at the end of their vacation. "Bye, house" is the last line spoken in Archipelago as the cleaners arrive, and the family vacates the rooms. In Exhibition there is no reason why the couple want to sell their home and move on, but we finally understand that - despite a short dreamlike flashback of the couple as newlyweds running up the stairs - there is no substantial personal history seeped into the walls of the house, just art. The edifice acts like a piece of interactive installation shaped by the people who live there and, in turn, shaping the lives of its occupants, embodying and housing desires and anxieties to make art and to "live" the art. The paraphrases of The Ecstasy of Saint Teresa in form of tableaux vivants that the woman protagonist repeatedly performs are as much about self-expression through her bond with Bernini's sculpture as about the expression of the symbiosis between her body, her artistic persona, and

31 Following their introduction by O'Doherty (1976) these notions have been widely theorized in art history, see for example, Uroskie (2014).

32 This aesthetics of fragmentation is probably related to Andersson's longstanding work as a prolific director of advertisements and short films. 
the house. Bernini's Saint Teresa, displayed in an aedicule of the church Santa Maria della Vittoria in Rome [Fig. 67], designed as a small theatre, may perhaps be seen not only as an image blending bodily and spiritual joy in the moment of transverberation, but as a prototype for a sculpture conceived as a performance and as the portrayal of a woman passionately blending in with architecture. ${ }^{33} \mathrm{In}$ the same vein, Hogg's heroine repeatedly folds her body around the corners of the rooms, hugging parts of the house in quiet moments of solitude [Figs. 89-90], while the house itself seems to fold over her body, as the pattern of the Venetian blinds on the windows and the straight lines of the house are echoed in the various striped outfits that she wears.

Thus, the house both encloses around her while she is immersed in her private, interactive "performance," and opens up as a theatrical space, a "white cube" inside the film, that we may observe from all sides and angles [Figs. 91-92]. ${ }^{34}$ From the outside it displays the reflection of the branches and leaves projected onto the large window pane exhibited as an abstract image facing the viewer, and it reveals the woman's private performance as a partially veiled peep-show through the striped openings of the blinds. In several scenes viewed both from the inside and outside it appears like a glass cage floating above the street, enframing and deframing a fragment of the visible world. As a cubic container, the house sometimes appears not only as an elegant piece of modernist architecture, but as a disconcerting maze consuming the nerves of the heroine with its strange noises, multiple compartments and moveable walls. It emerges even like a futuristic greenhouse of human habitation nesting an amazing collection of plants together with rocks, artefacts and pieces of modern technology. The staircase that looks like a metallic DNA spiral epitomizes the connection between the natural and the artificial [Figs. 66, 89], transforming the construction into a kind of modern day Leviathan that has engulfed its

33 Joanna Hogg also mentions the influence of Gaston Bachelard's Poetics of Space in thinking about the house as a living organism, a vessel of memory and feeling, and the inspiration drawn from Louise Bourgeois's series called Femme Maison, "about woman and building integrated; woman as house." See the online interview in CineVue: http://www.cine-vue.com/2014/06/ interview-joanna-hogg-unravels.html. Last accessed 25. 08. 2015.

34 The empty room already devoid of furniture shown in the film looks uncannily similar to an actual exhibition space [Fig. 92] reminding us at the same time how a "white cube" is never a neutral container but a modern architectural space which is often exploited for its interaction with the art hosted within its walls. "The walls assimilate, the art discharges," writes O'Doherty (1986, 79). Moreover, in certain cases the exhibition hall itself becomes the exhibition, context becomes content (see Doherty 1986, 65-86). Hogg's film spotlights this interdependence: the house exhibits its content (the life of the married couple, their dreams and their actions), and is exhibited for us to see as an active protagonist alongside the characters inhabiting it. 
inhabitants and offers them a cocoon-like space destined for self-reflection and artistic creation, resonating with their emotions, flexible in accommodating their creative work, but also apparently having a life of its own.

As a final act of performance at the farewell party, the protagonists, identified only with their initials D. and H. ${ }^{35}$ reverse this relationship by marking their separation from the house in a symbolic act of dismembering and eating the building in the form of a cake replica that they serve to their guests. Joanna Hogg's house can be seen in this way as the quintessential model for the "architecture" of the post-cinematic tableau, as the perfect vision of the white cube of modern art space being symbolically incorporated, metabolised by contemporary cinema. This also shows how cinema can feed on architecture, sculpture, painting, and performance while slowly moving in the direction of gallery art.

\section{References}

Alpers, Svetlana. 1983. The Art of Describing. Dutch Art in the Seventeenth Century. Chicago: University of Chicago Press.

Balázs, Béla. 2010 [1924, 1930]. Early Film Theory: Visible Man and The Spirit of Film. New York and Oxford: Berghahn Books.

Bellour, Raymond. 2007 [1984]. The Pensive Spectator. In The Cinematic, ed. David Campany, 119-123. London: Whitechapel and Cambridge, Massachusetts: MIT Press.

Blom, Ivo. 2010. Frame, Space, Narrative. Doors, Windows and Mobile Framing in the Films of Luchino Visconti. Acta Universitatis Sapientiae: Film and Media Studies vol. 2: 91-107.

Bonitzer, Pascal. 2000 [1978]. Deframings. In Cahiers du Cinéma. Volume Four: 1973-1978: History, Ideology, Cultural Struggle, ed. David Wilson, 196-203. London and New York: Routledge.

Bordwell, David. 1981. The Films of Carl Theodor Dreyer. Berkeley, Los Angeles: University of California Press.

Bordwell, David. 1988. Ozu and the Poetics of Cinema. London, Princeton: BFI Publishing, Princeton University Press.

Brewster, Ben and Lea Jacobs. 1998. Theatre to Cinema: Stage Pictorialism and the Early Feature Film. Oxford: Oxford University Press.

35 This may remind us, perhaps, of another, majestically haunting film that featured an impressive architectural space related to the protagonists' visions and desires, Last Year in Marienbad (L'année dernière à Marienbad, 1962) directed by Alain Resnais. 
Burch, Noël. 1979. To the Distant Observer: Form and Meaning in the Japanese Cinema. Berkeley, Los Angeles: University of California Press.

Chevrier, Jean-François. 2003. The Adventures of the Picture Form in the History of Photography. In The Last Picture Show: Artists Using Photography, 19601982, ed. Douglas Fogle, 113-128. Minneapolis: Walker Art Center.

Chevrier, Jean-François. 2006. The Tableau and the Document of Experience. In Click Double Click: The Documentary Factor, ed. Weski, Thomas, 51-61. Köln: Walther König.

Cole, Georgina. 2006. Wavering between Two Worlds: the Doorway in SeventeenthCentury Dutch Genre Painting. Philament vol. 9: 1-37. http://sydney.edu.au/ arts/publications/philament/issue9_pdfs/COLE_Doorways.pdf. Last accessed 25. 08. 2015.

Forrest, David. 2014. The Films of Joanna Hogg: New British Realism and Class. Studies in European Cinema vol. 11 no.1: 64-75.

Fried, Michael. 1988. Absorption and Theatricality: Painting and Beholder in the Age of Diderot. Chicago: University of Chicago Press.

Fried, Michael. 1992. Courbet's Realism. Chicago: University of Chicago Press.

Fried, Michael. 1998a. Art and Objecthood: Essays and Reviews. Chicago: University of Chicago Press.

Fried, Michael. 1998b. Manet's Modernism: or, The Face of Painting in the 1860s. Chicago: University of Chicago Press.

Fried, Michael. 2008. Why Photography Matters as Art as Never Before. New Haven: Yale University Press.

Fried, Michael. 2011. Four Honest Outlaws. Sala, Ray, Marioni, Gordon. New Haven: Yale University Press.

Fried, Michael. 2015. Another Light. Jacques-Louis David to Thomas Demand. New Haven: Yale University Press.

Hammer-Tugendhat, Daniela. 2015 [2009]. The Visible and the Invisible: On Seventeenth-Century Dutch Painting. Berlin, Munich, Boston: Walter de Gruyter.

Hanich, Julian. 2014. Complex Staging. The Hidden Dimensions of Roy Andersson's Aesthetics. Movie - A Journal of Film Criticism vol. 5: 37-50.

Hollander Martha. 2002. An Entrance for the Eyes: Space and Meaning in Seventeenth-Century Dutch Art. Berkeley, Los Angeles, London: University of California Press.

Loxley, James. 2007. Performativity. London, New York: Routledge. 
O’Doherty, Brian. 1986 [1976]. Inside the White Cube. The Ideology of the Gallery Space. Santa Monica, San Francisco: The Lapis Press.

Mulvey, Laura. 2006. Death $24 \times$ a Second. Stillness and the Moving Image. London: Reaktion Books.

Pethő, Ágnes. 2011. Cinema and Intermediality. The Passion for the In-Between. Newcastle upon Tyne: Cambridge Scholars Publishing.

Pethő, Ágnes. 2014. The Garden of Intermedial Delights: Cinematic 'Adaptations' of Bosch, from Modernism to the Postmedia Age. Screen vol. 55 no. 4 (Winter): 471-489.

Pethő, Ágnes. 2015. Figurations of the Photofilmic: Stillness versus Motion Stillness in Motion. In The Photofilmic. Entangled Images in Contemporary Art and Visual Culture, eds. Brianne Cohen and Alexander Streitberger, 221243. Leuven: Leuven University Press, Lieven Gevaert Series.

Peucker, Brigitte. 2007. The Material Image. Art and the Real in Film. Stanford: Stanford University Press.

Pop, Doru. 2014. Romanian New Wave Cinema. An Introduction. Jefferson, North Carolina: McFarland \& Company, Inc. Publishers.

Rice, Charles. 2007. Emergence of the Interior: Architecture, Modernity, Domesticity. New York: Routledge.

Stoichita, Victor I. 1997. The Self-Aware Image: An Insight into Early Modern Meta-Painting. Cambridge: Cambridge University Press.

Toop, David. 2010. Sinister Resonance. The Mediumship of the Listener.

London: Continuum.

Uroskie, Andrew V. 2014. Between the Black Box and the White Cube:

Expanded Cinema and Postwar Art. Chicago, London: University of Chicago Press.

Vidal, Belén. 2012. Figuring the Past. Period Film and the Mannerist Aesthetic. Amsterdam: Amsterdam University Press.

Wall, Jeff. 2007 [1989]. Photography and Liquid Intelligence. In Selected Essays and Interviews, 109-110. New York: MOMA.

Westermann, Mariët. 1996. The Art of the Dutch Republic, 1585-1718. London: Laurence King Publishing. 


\section{List of Figures}

Figures 1-4. Antonello da Messina: St. Jerome in his Study (1460-1475), Pieter de Hooch: A Mother Delousing her Child's Hair, also known as A Mother's Duty (1658-1660), Young Woman with a Letter and a Messenger in an Interior (1670), Samuel van Hoogstraten: View of an Interior, or The Slippers (1654-1662).
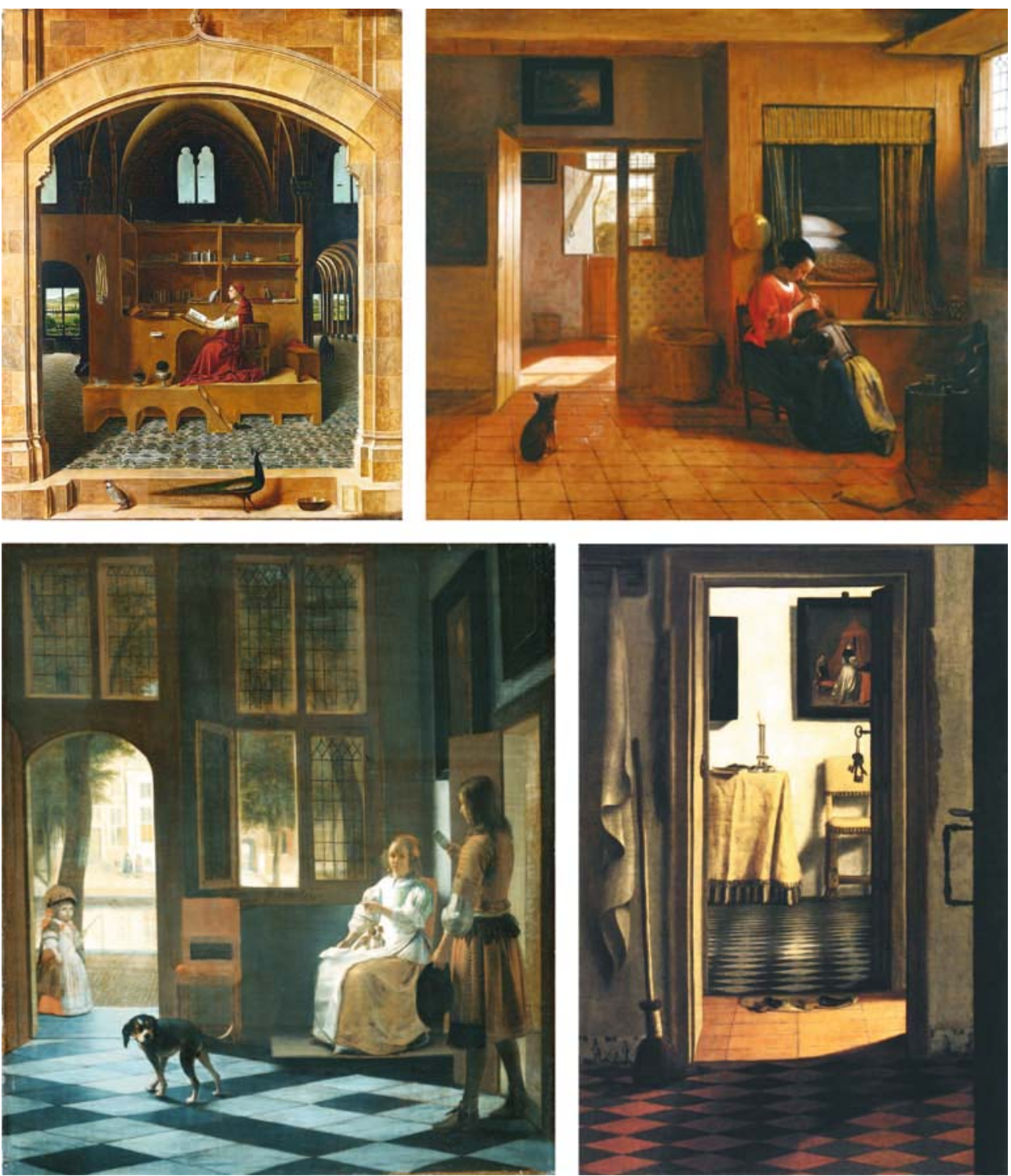
Figures 5-6. Samuel van Hoogstraten: Peepshow with Views of the Interior of a Dutch House (1655-1660), Pieter de Hooch: Courtyard of a House in Delft (1658).
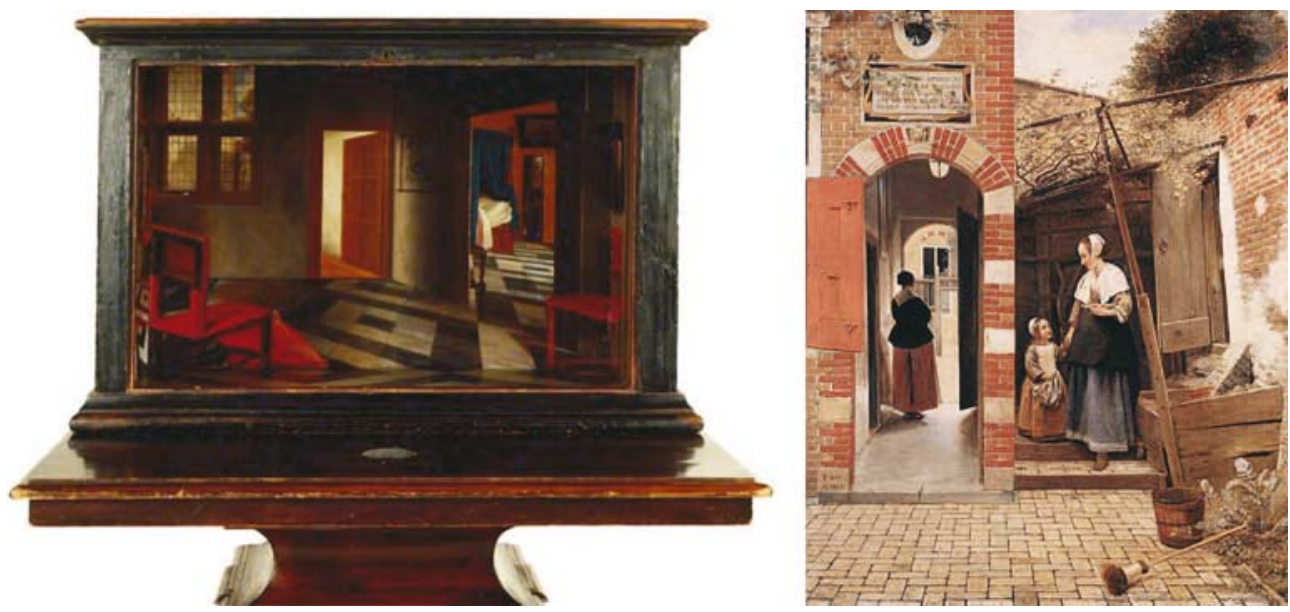

Figures 7-8. Nicoales Maes: The Eavesdropper (1655-1656), The Listening Housewife (The Eavesdropper, 1656).
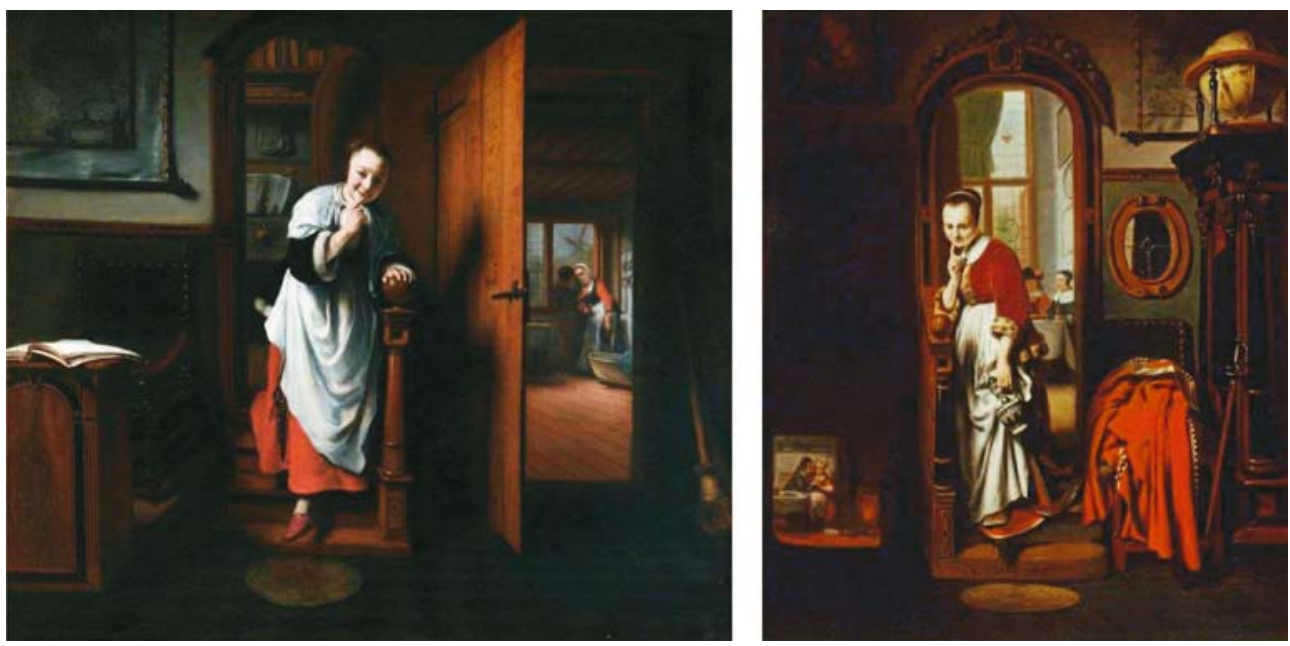
Figures 9-12. Life contained within cubic spaces erasing the difference between domestic and public locations: frame-grabs from Roy Andersson's films (9-10: You, the Living; 11-12: A Pigeon Sat on a Branch Reflecting on Existence).
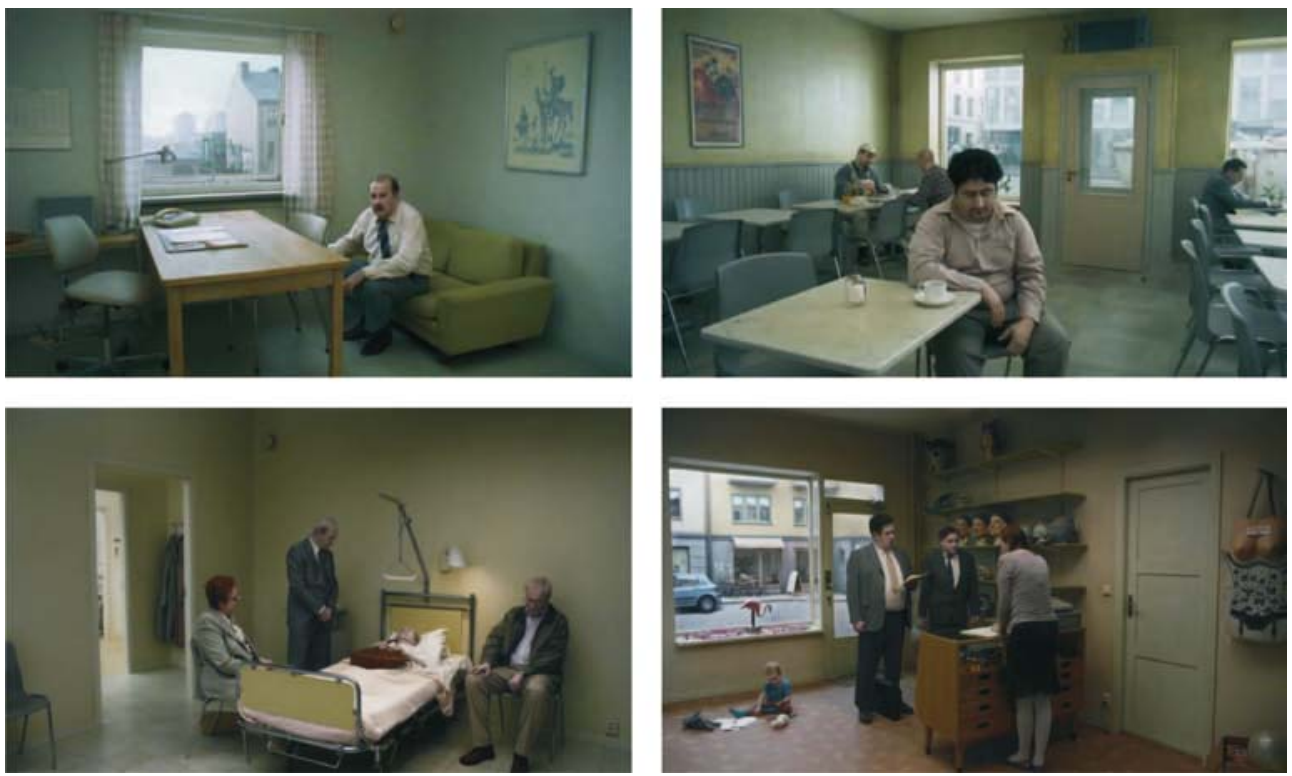

Figures 13-20. Structured interiors, social dynamics reflected in architectural spaces in Joanna Hogg's films (13-14: Unrelated; 15-20: Archipelago).
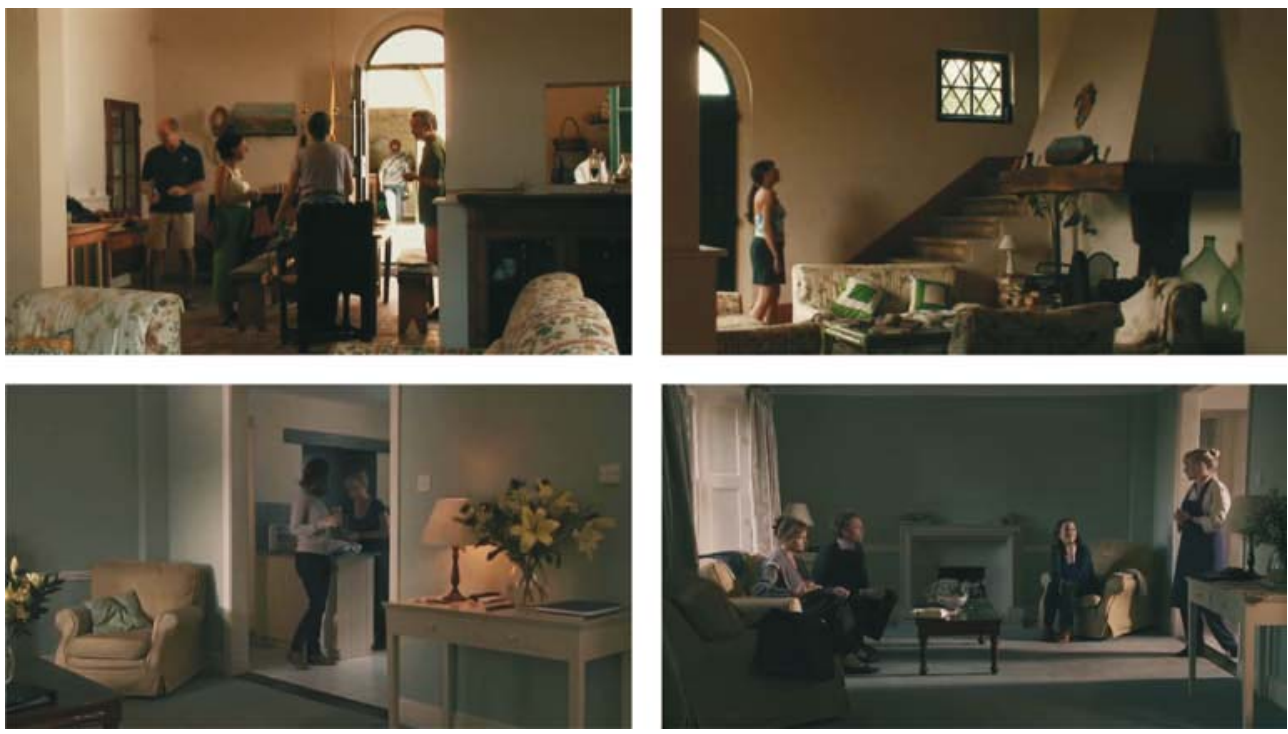

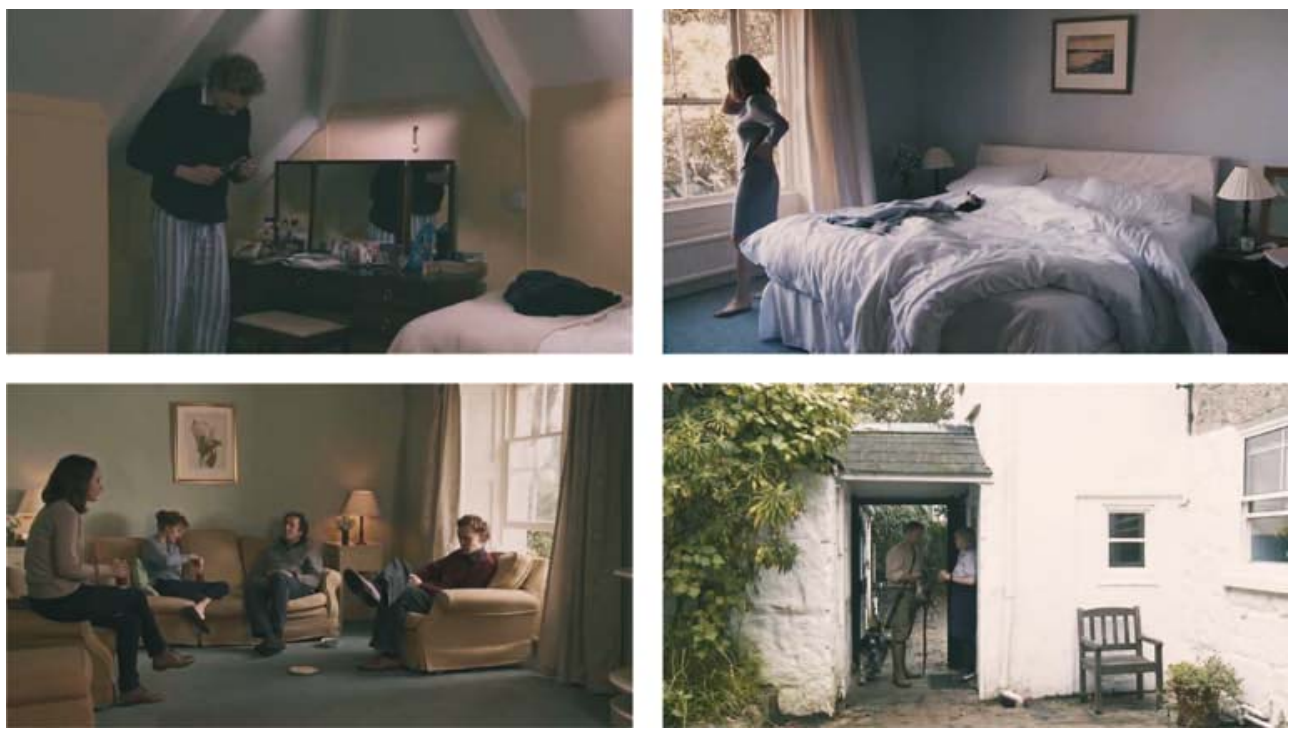

Figures 21-24. 12.08. East of Bucharest: a series of tableaux of domestic interiors: the talk show participants in their natural "habitat."
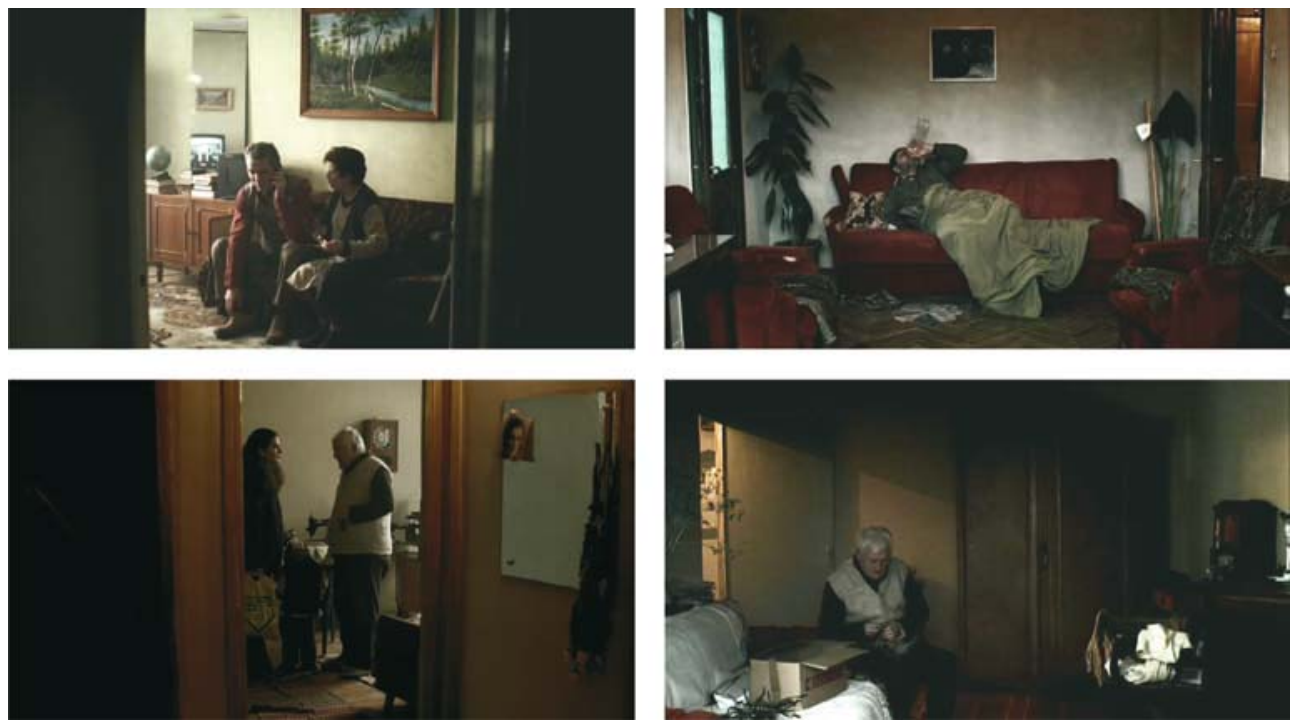
Figures 25-28. The "chamber art" structure used for satirical purposes in Roy Andersson's films. (25-26: A Pigeon Sat on a Branch Reflecting on Existence; 27-28: You, the Living.)
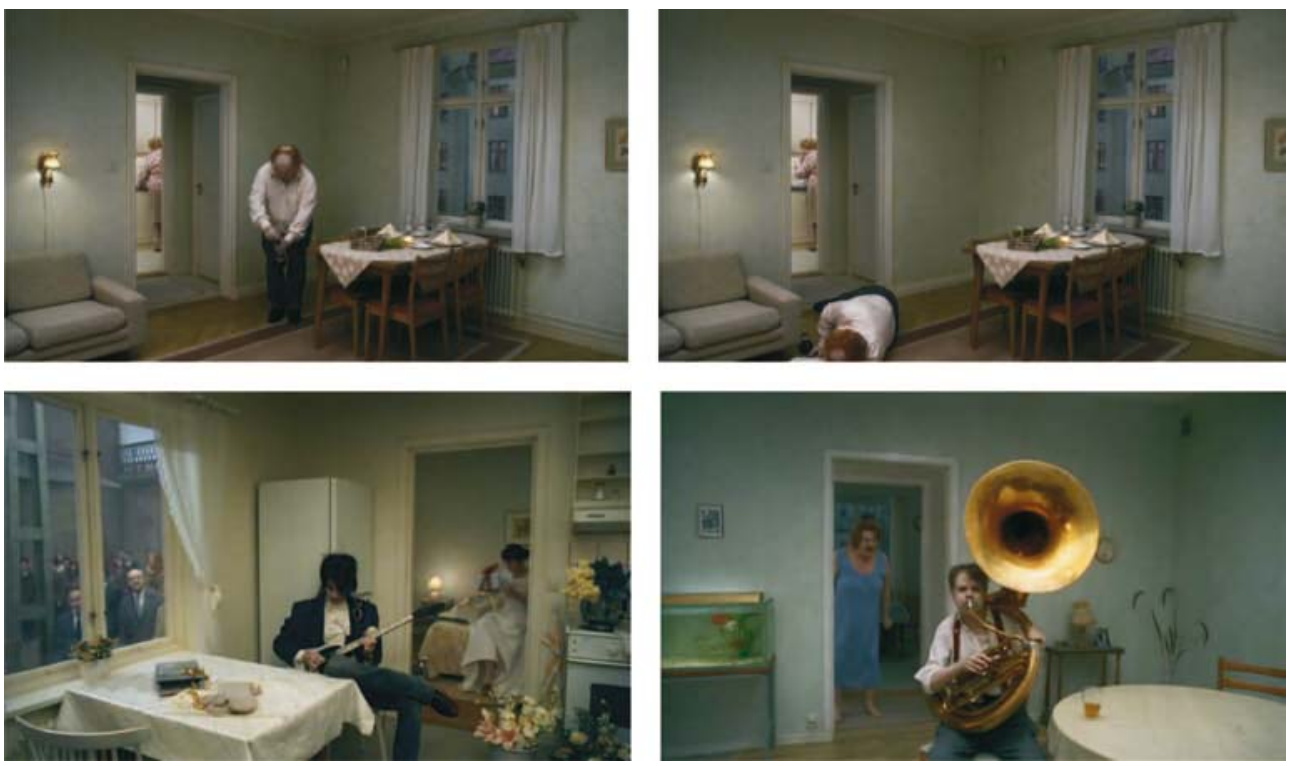

Figures 29-30. Characters appearing as if moving on a stage in Hogg's Unrelated.
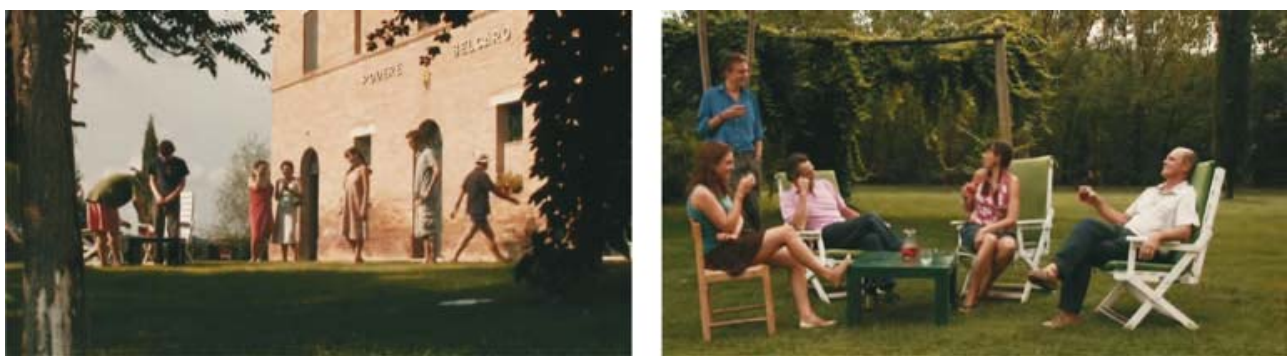

Figures 31-32. The passage from "domestic chamber" to diorama, or "exhibition case” in Joanna Hogg's Exhibition.
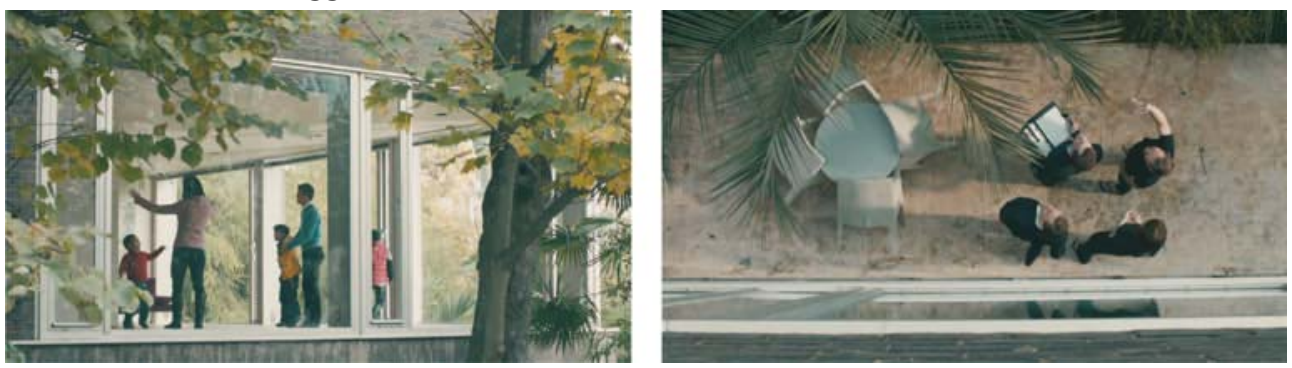
Figures 33-34. Aquarium-like spaces in Porumboiu’s 12:08. East of Bucharest.
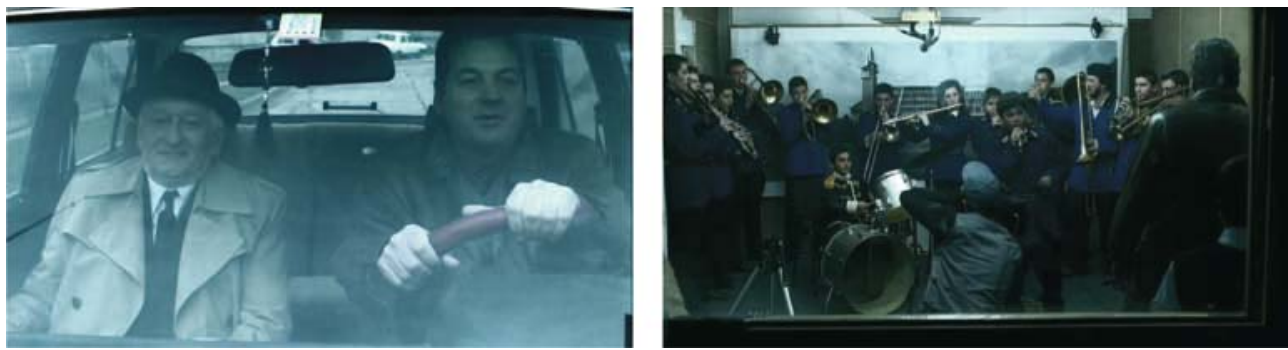

Figures 35-38. Characters boxed in glass cases in Roy Andersson's films (3536: You, the Living; 37-38: A Pigeon Sat on a Branch Reflecting on Existence).
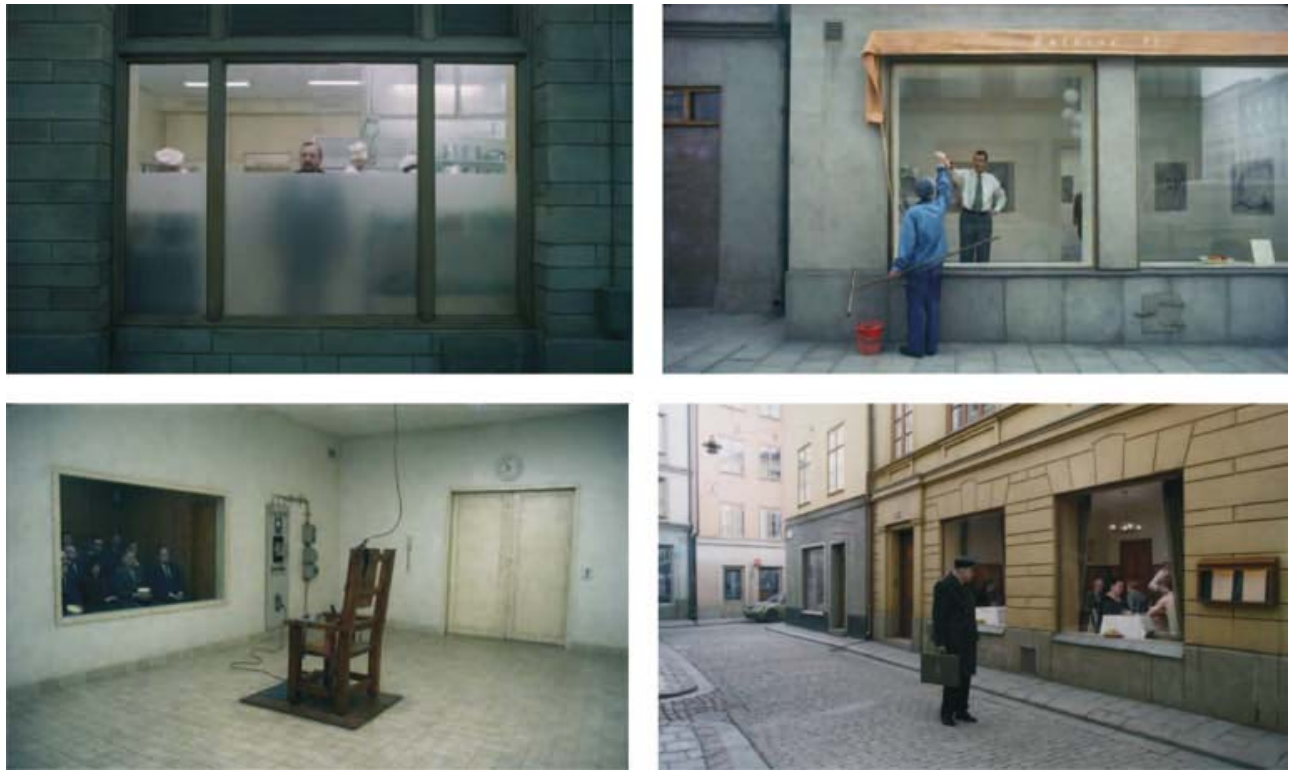

Figures 39-40. A motif taken from Pieter Bruegel the Elder: Hunters in the Snow (1565): birds looking down on humans: a double diorama, boxing in both the birds and the humans as waxwork figures in Andersson's A Pigeon Sat on a Branch Reflecting on Existence.
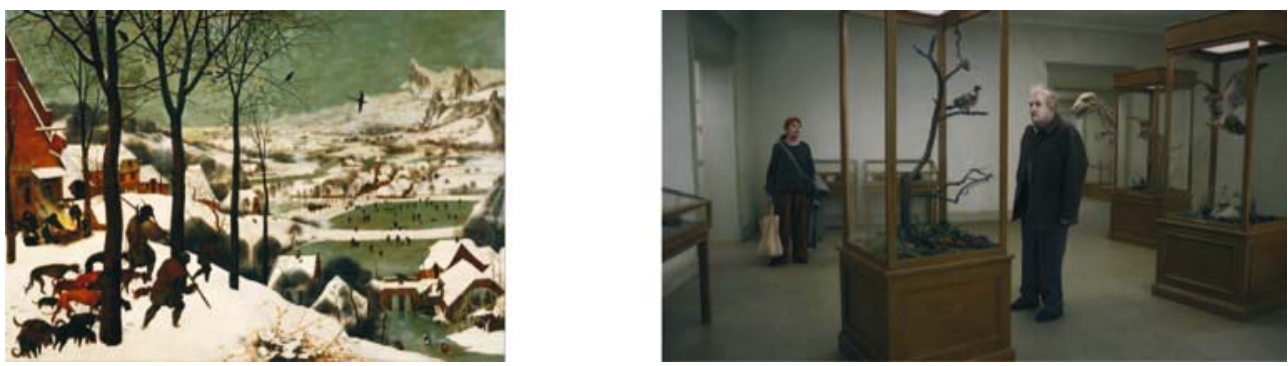
Figures 41-44. The end of 12:08. East of Bucharest: a hilarious decomposition of the tableau (and the arrangement of the figures as a secularized "holy trinity").
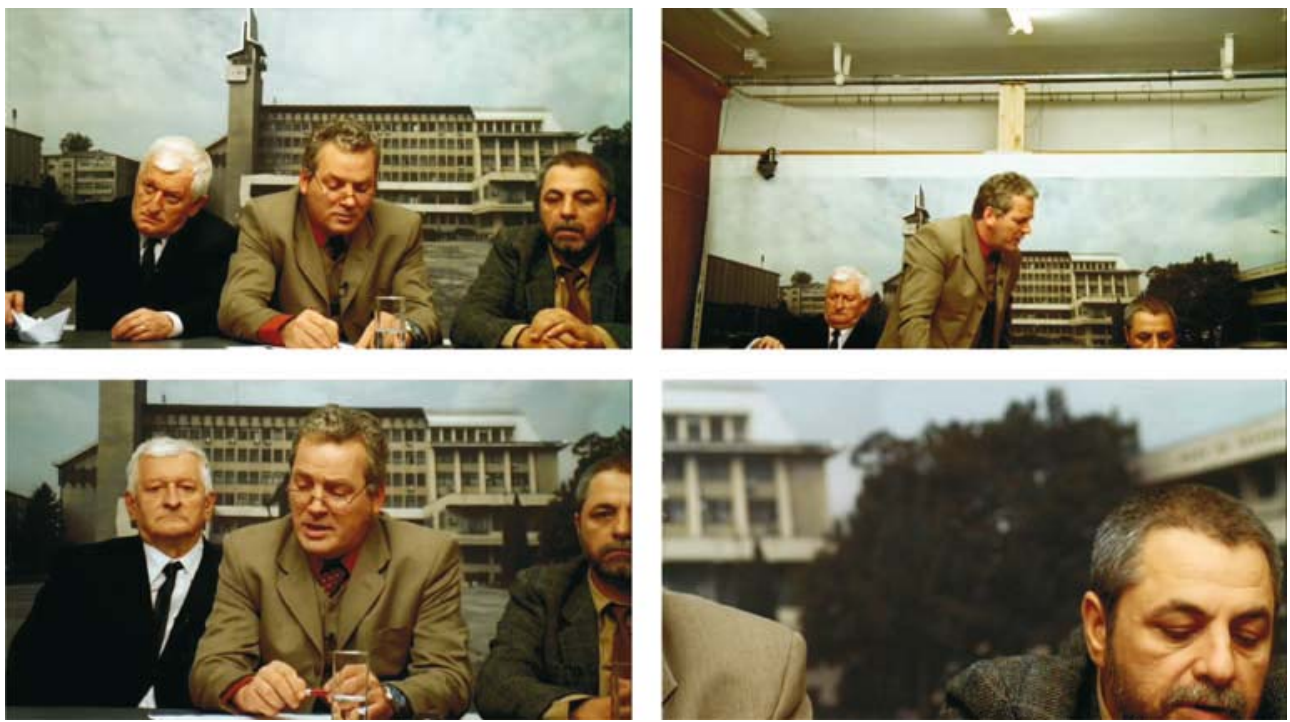

Figures 45-48. Rich signification of inventive framings versus de-framings ranging from melancholy, isolation, insensitivity to pure visual abstraction in Joanna Hogg's films (45: Unrelated, 46: Archipelago, 47-48: Exhibition).
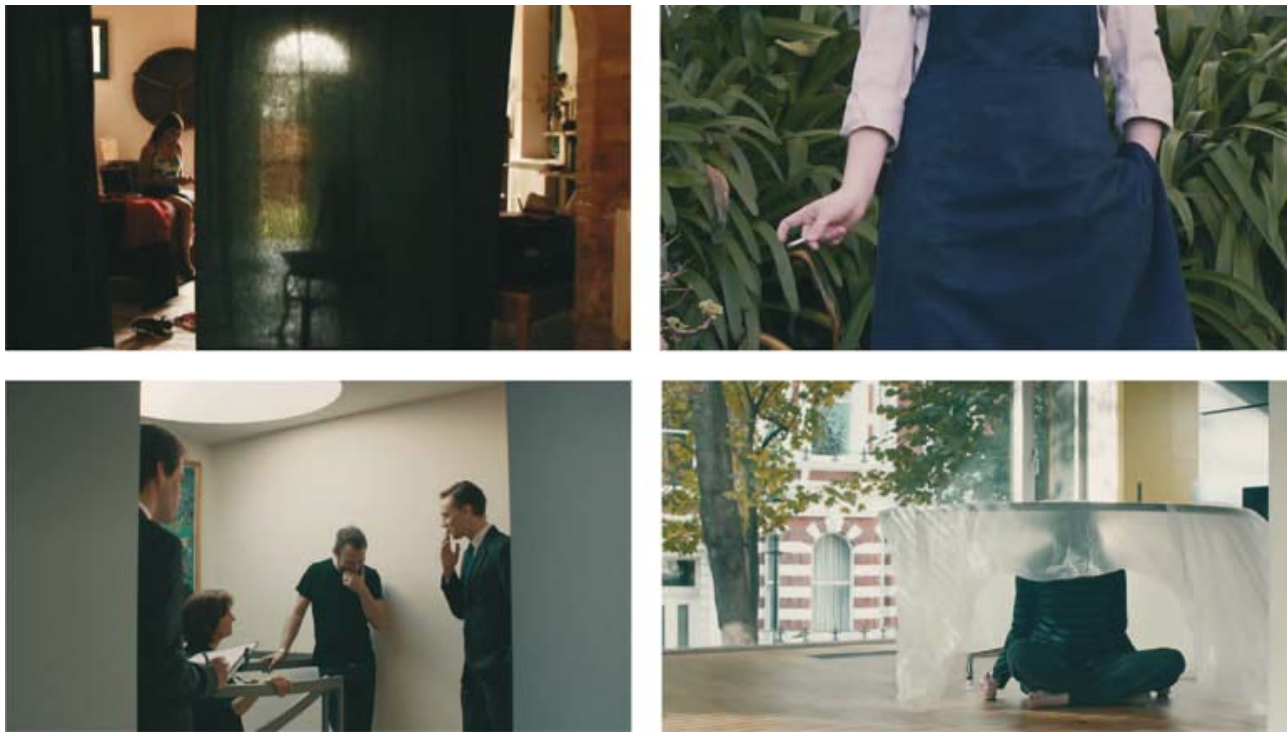
Figures 49-50. The emphasis on "being in the frame" in Hogg's Unrelated and Archipelago.
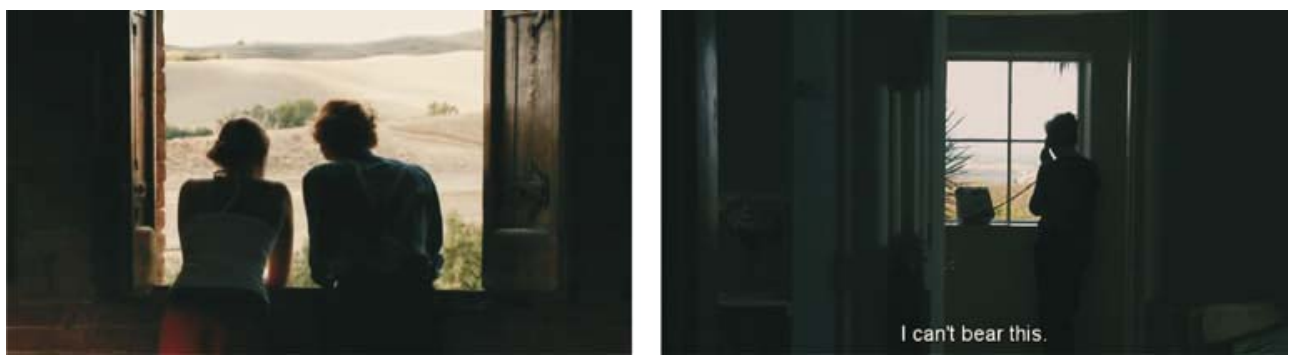

Figures 51-54. The figure of the eavesdropper in Hogg's Unrelated and Archipelago.
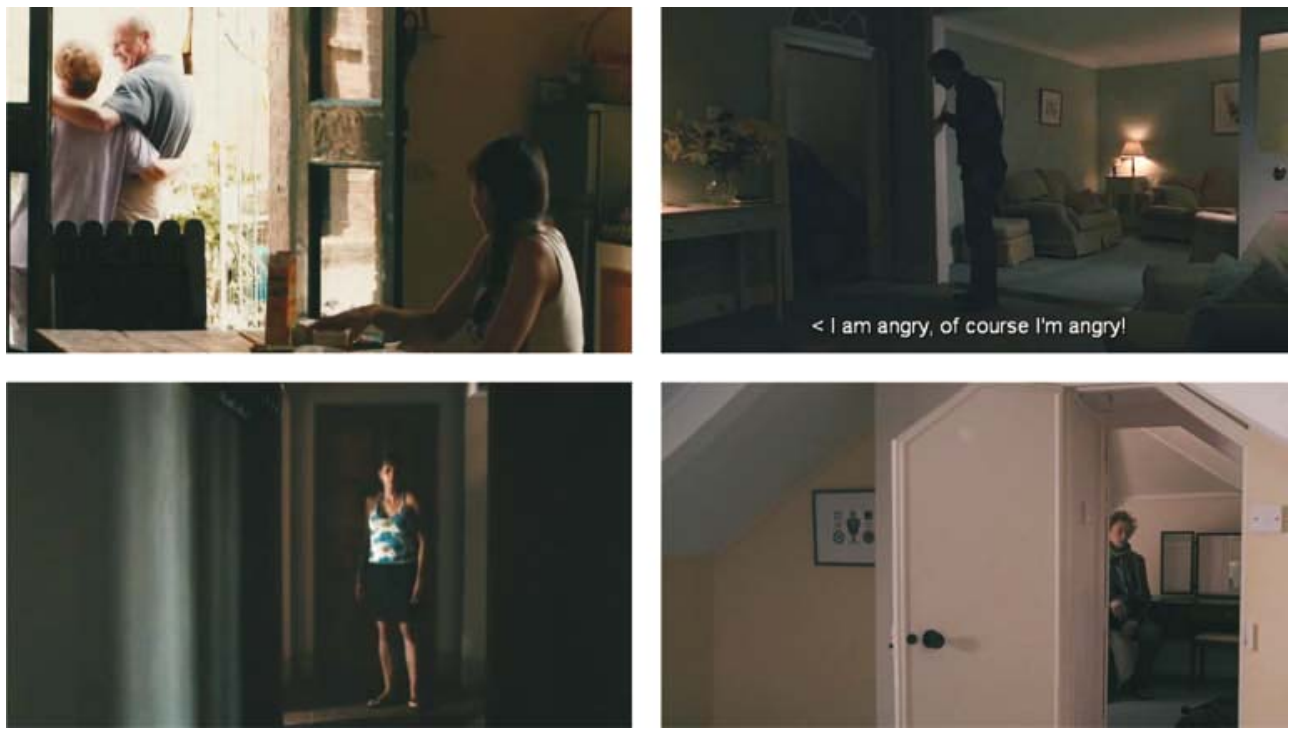

Figures 55-58. Corneliu Porumboiu’s Police, Adjective (2009).
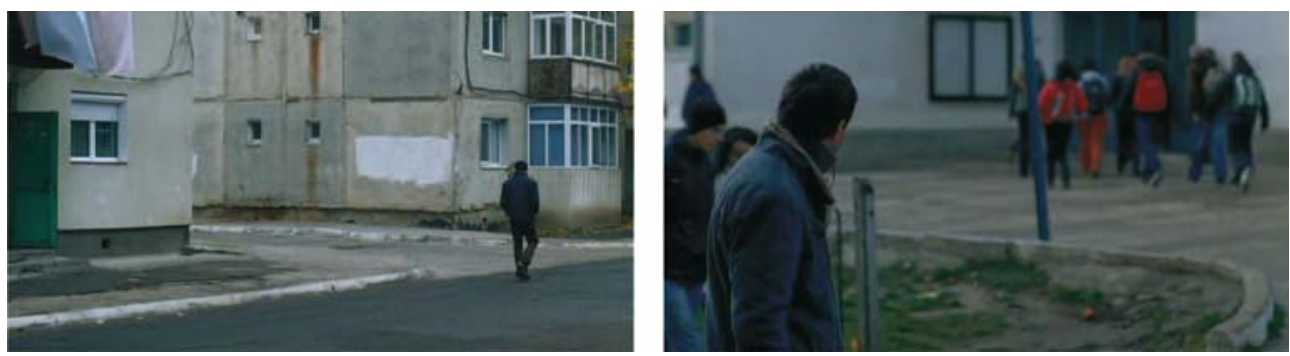

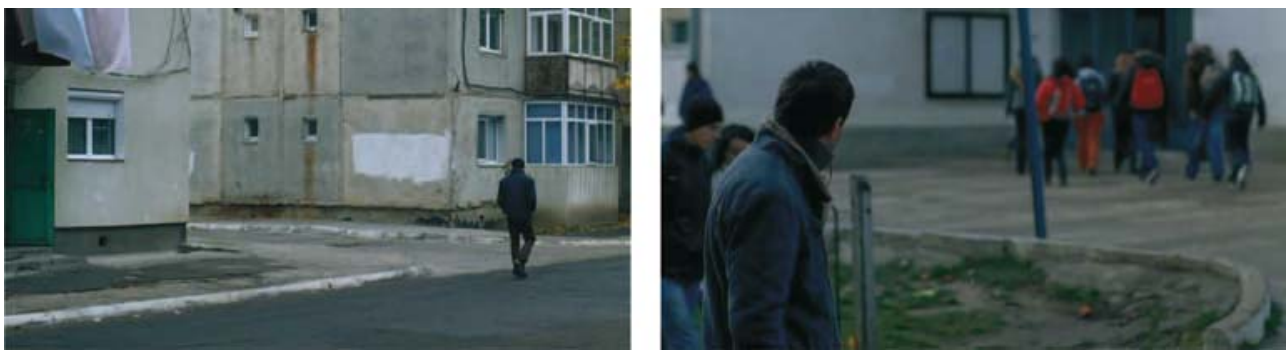

Figures 59-60. Tableau scene in Roy Andersson's A Pigeon Sat on a Branch Reflecting on Existence inspired by the painting of Jean-François Millet, Noonday Rest (1866).
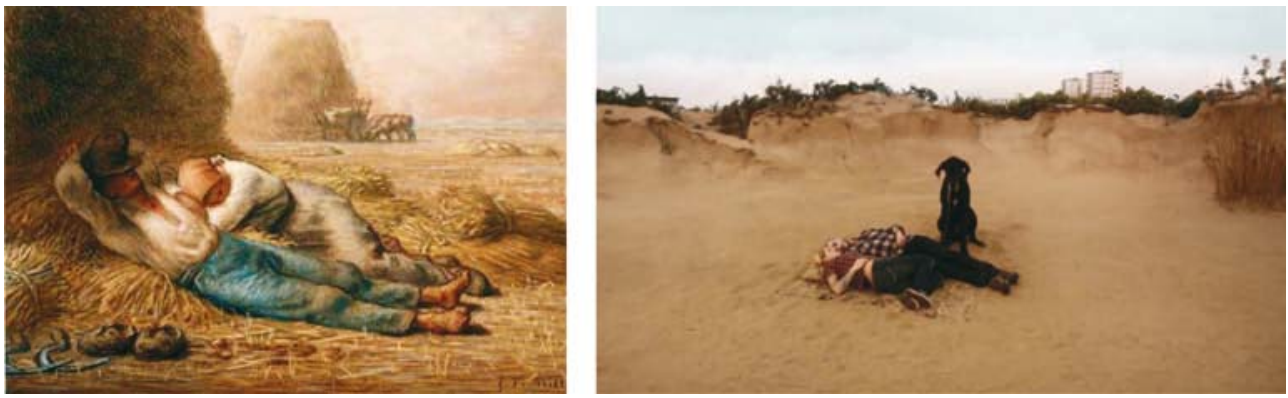

Figures 61-62. Joanna Hogg's Archipelago: observing the world in terms of painting.
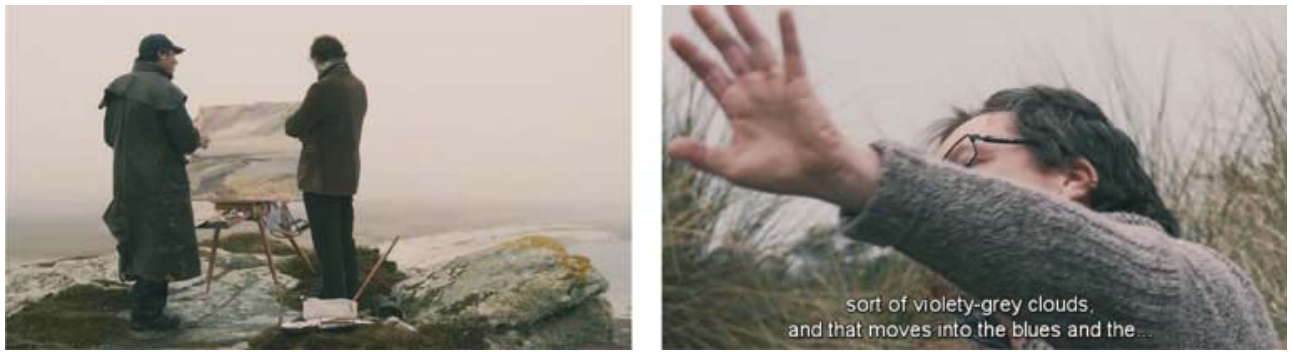

Figures 63-66. The house as an artwork in Joanna Hogg's Exhibition.
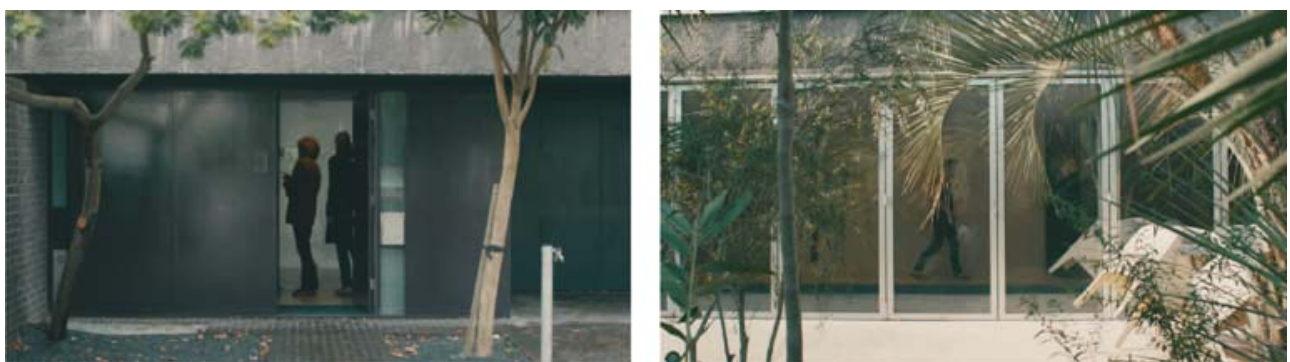

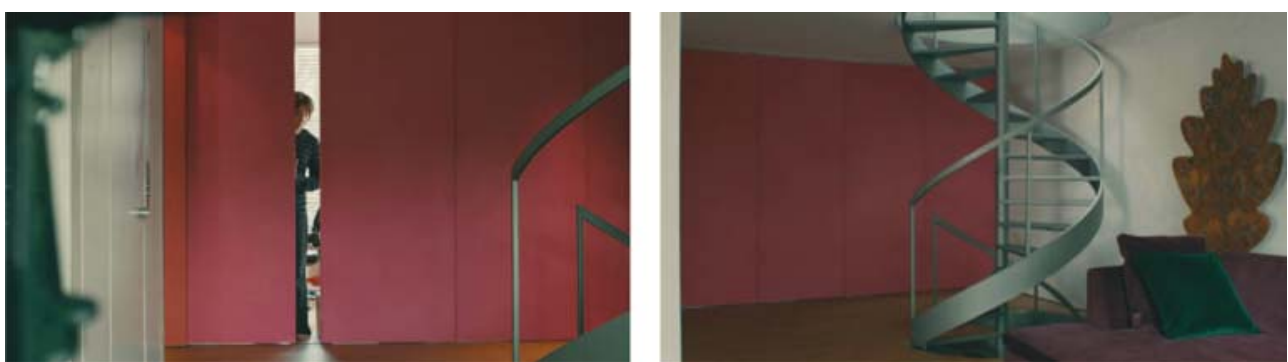

Figures 67-70. Staging the re-embodiment of Gian Lorenzo Bernini's Ecstasy of Saint Teresa (1647-1652).
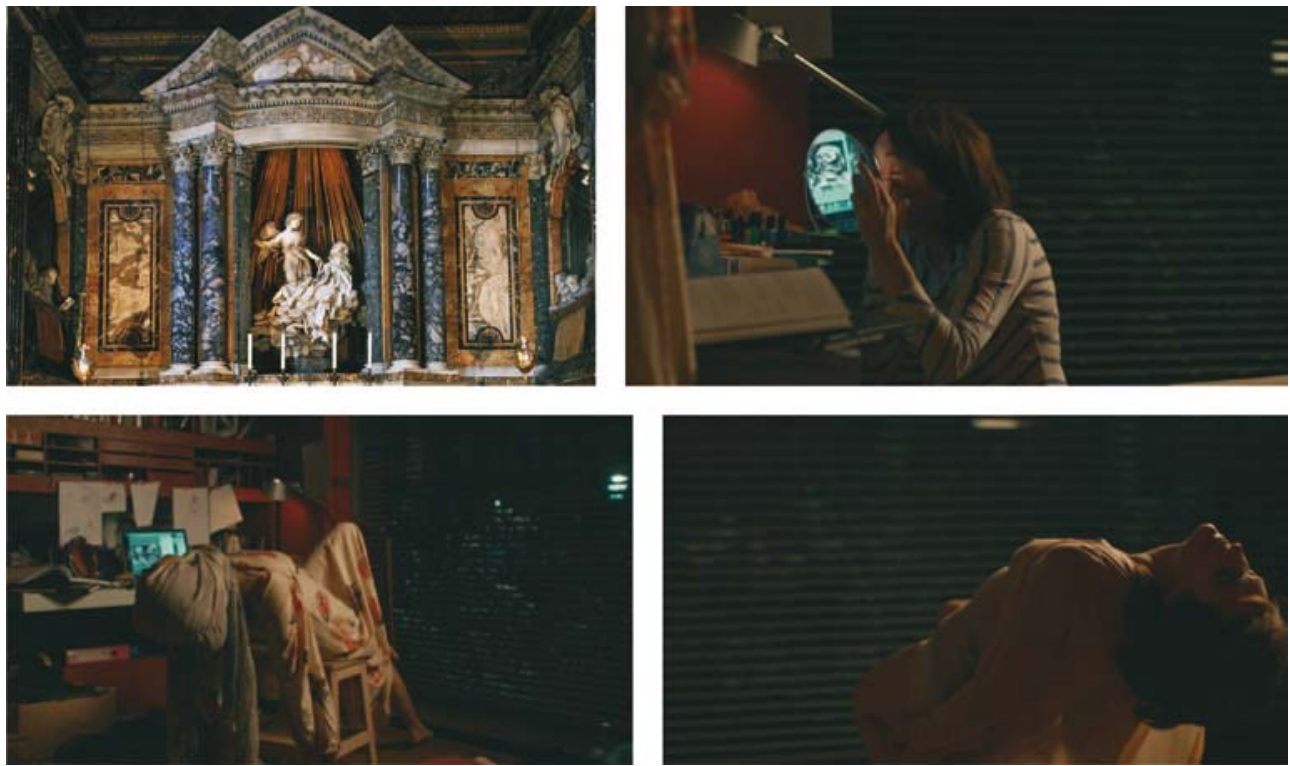

Figures 71-72. Porumboiu's Police, Adjective: the policeman deeply embedded in his world.
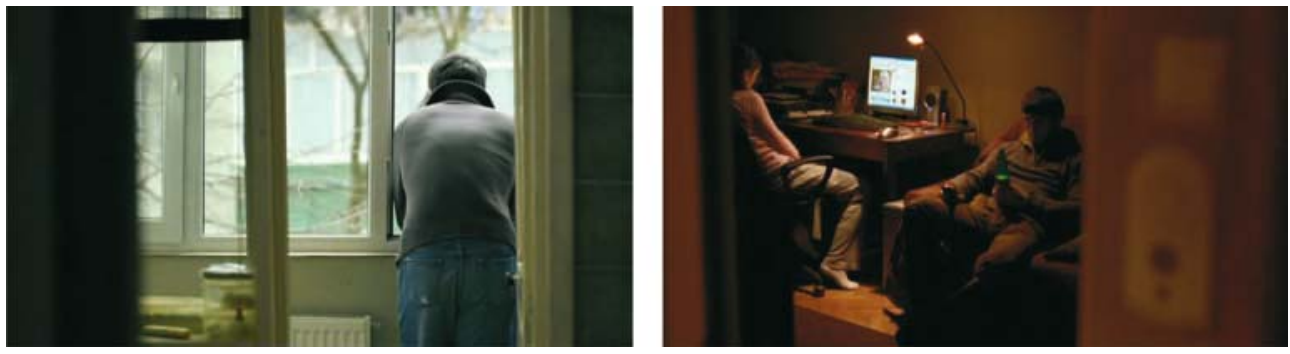
Figures 73-76. "Enframing:" containment, entrapment, the definition of the indefinite.
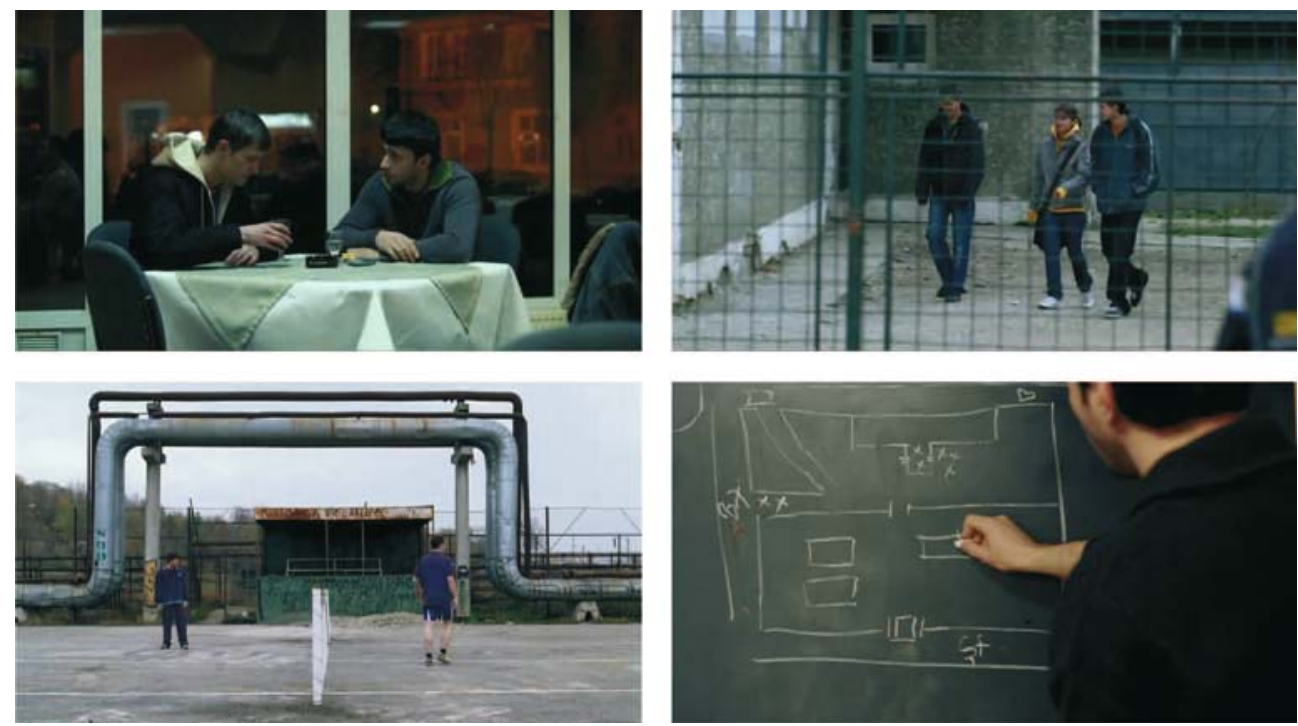

Figures 77-78. Andrei Rublev's Troitsa (1425-27) and the last tableau in Police, Adjective. A theatre of the "abstract:" reality traded in for entries in a dictionary.
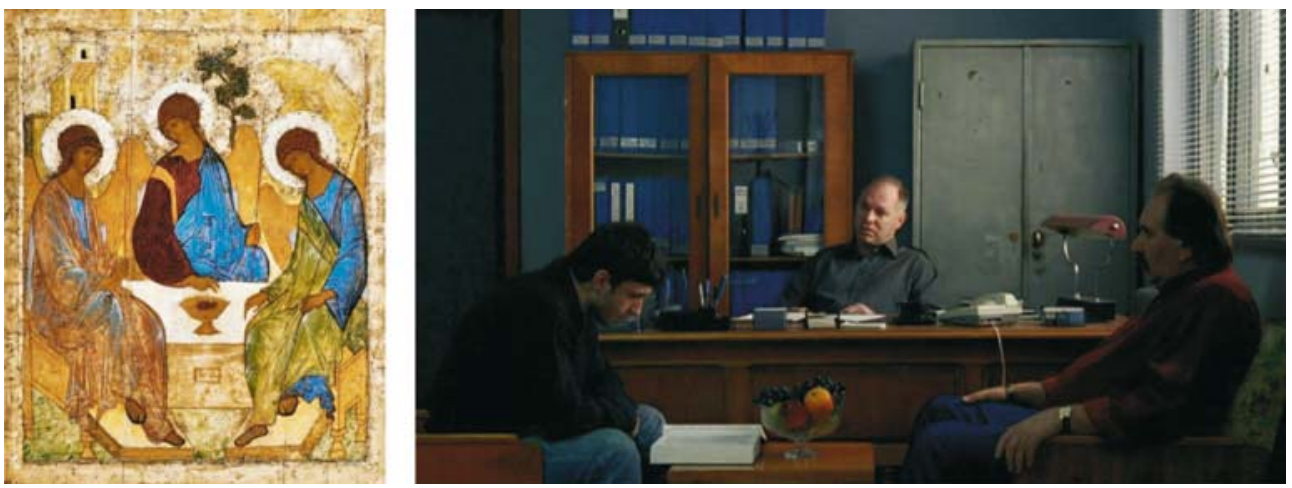
Figures 79-82. Liquidity vs. dry structure: Joanna Hogg's picturesque and sensuous outdoor scenes in Archipelago and Unrelated.
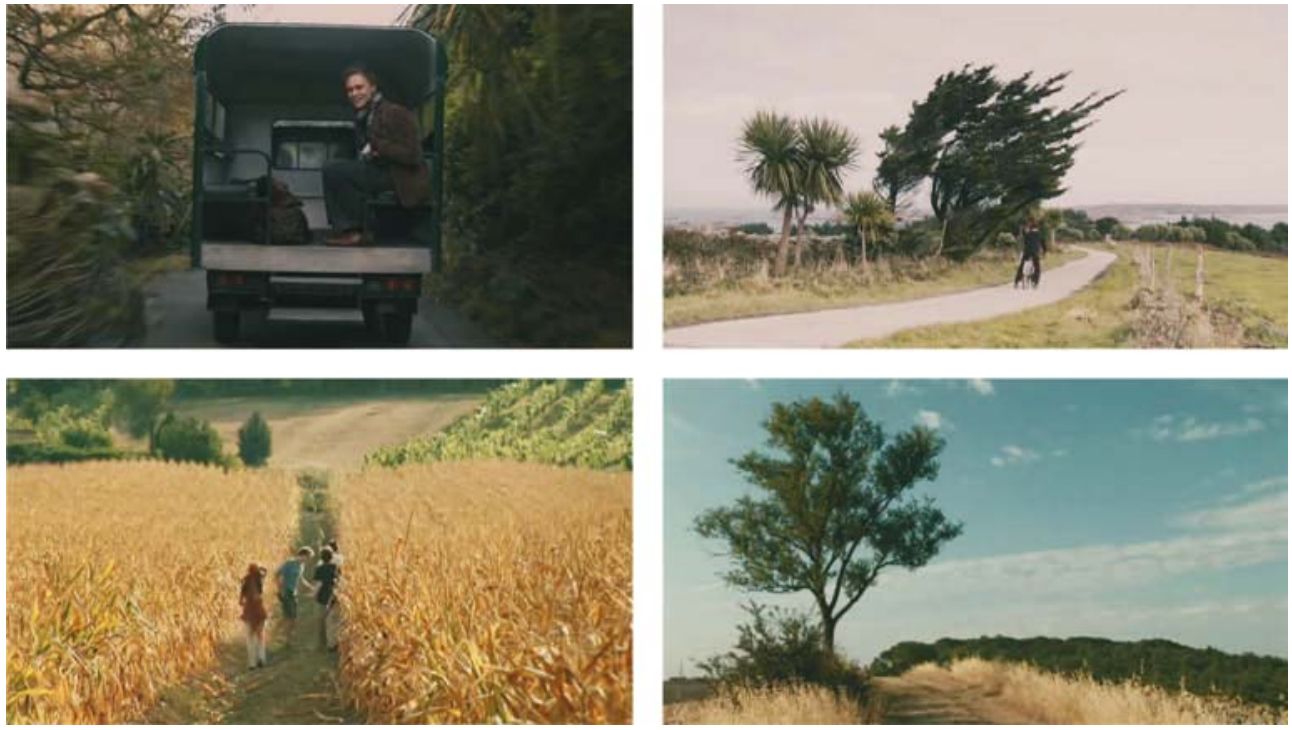

Figures 83-84. "The liquid intelligence" of photography pouring over the glassed-in tableau.
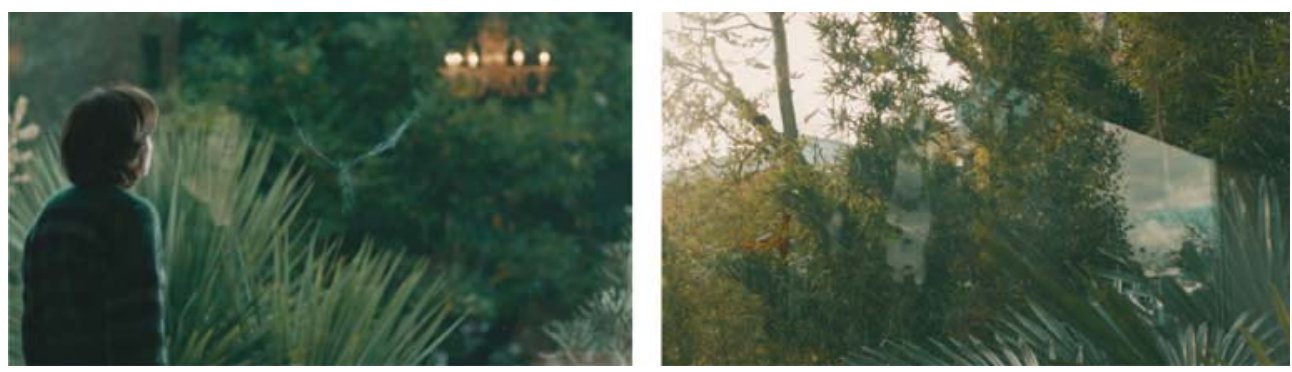
Figures 85-88. Corneliu Porumboiu's When Evening Falls on Bucharest, or Metabolism: variations on dialogues and prolonged tableau shots.
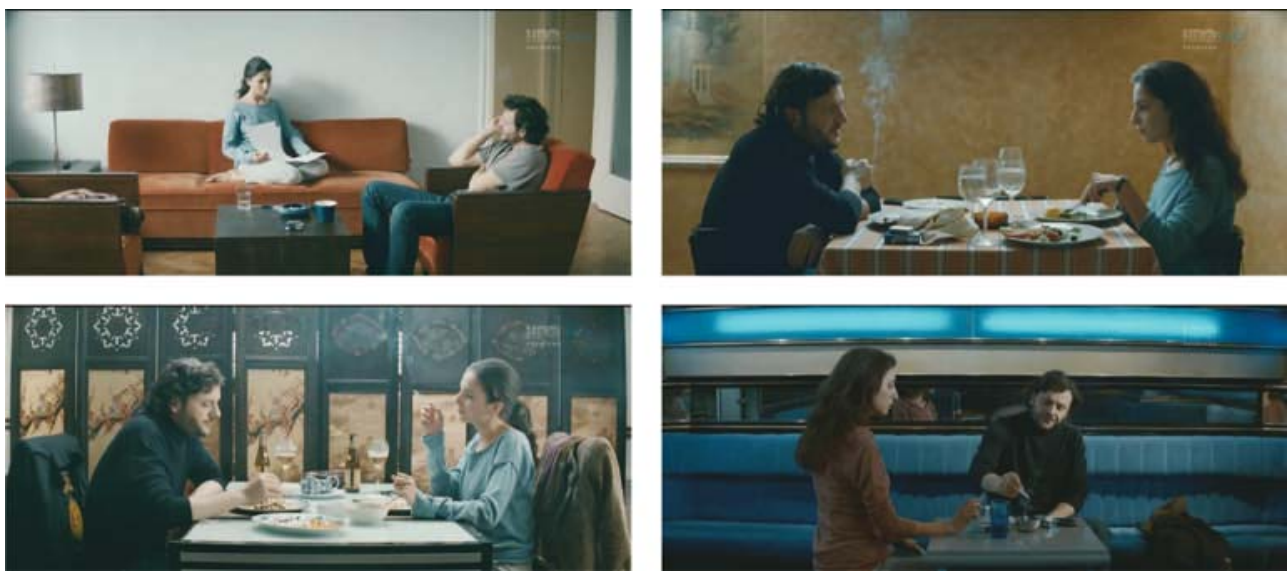

Figures 89-90. Folding over the body and the house in Exhibition.
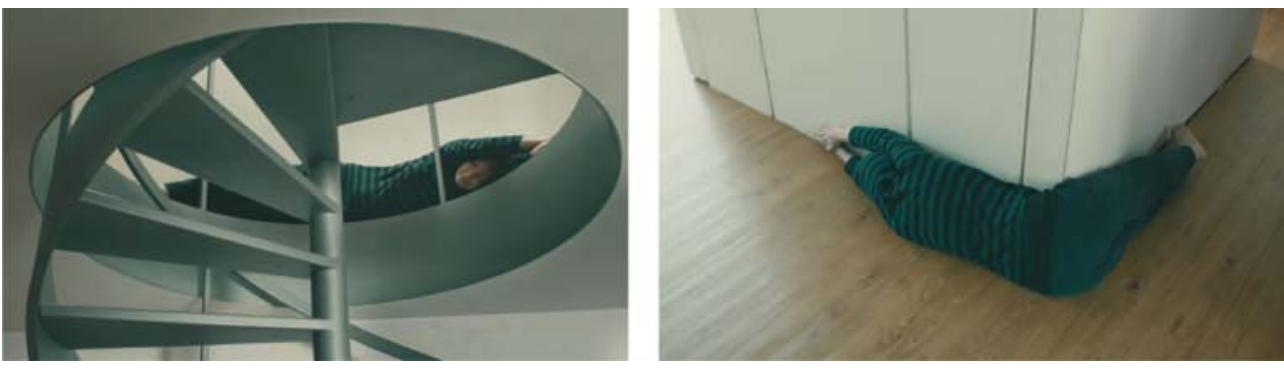

Figures 91-92. Joanna Hogg's house as an exhibition space in Exhibition.
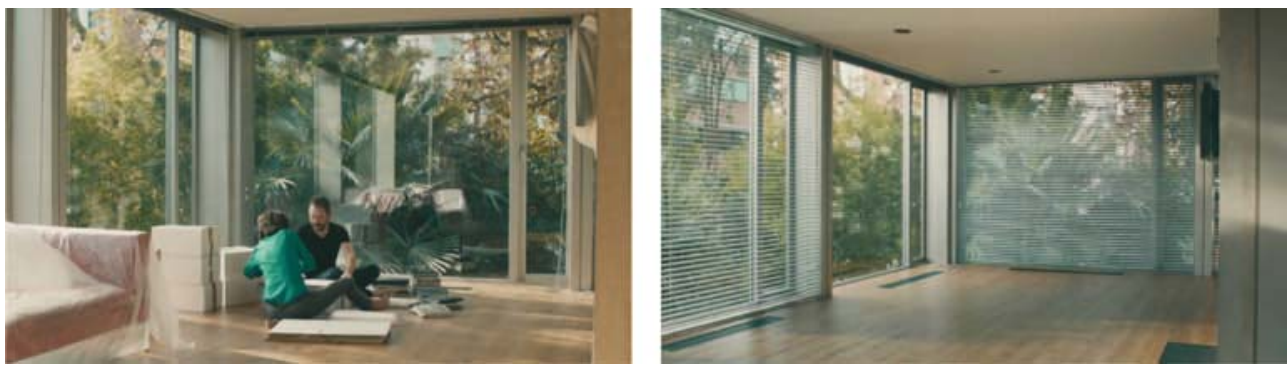